\title{
Distinct myeloid progenitor differentiation pathways identified through single cell RNA sequencing
}

Roy Drissen ${ }^{1,3}$, Natalija Buza-Vidas ${ }^{3}$, Petter Woll ${ }^{1,2}$, Supat Thongjuea ${ }^{1}$, Adriana Gambardella ${ }^{1,3}$, Alice Giustacchini ${ }^{1,2}$, Elena Mancini ${ }^{4}$, Alya Zriwil ${ }^{5}$, Michael Lutteropp ${ }^{1,2}$, Amit Grover ${ }^{1,3,4}$, Adam Mead ${ }^{1,2}$, Ewa Sitnicka ${ }^{5}$, Sten Eirik W. Jacobsen ${ }^{1,2,6,{ }^{*}}$ and Claus Nerlov ${ }^{1,3,4,6,{ }^{*}}$.

${ }^{1}$ MRC Molecular Hematology Unit, Weatherall Institute of Molecular Medicine, University of Oxford, Oxford, United Kingdom, ${ }^{2}$ Haematopoietic Stem Cell Laboratory, Weatherall Institute of Molecular Medicine, University of Oxford, Oxford, United Kingdom, ${ }^{3}$ Institute for Stem Cell Research, University of Edinburgh, Edinburgh, United Kingdom, ${ }^{4}$ EMBL Mouse Biology Program, Monterotondo, Italy and ${ }^{5}$ Division of Molecular Hematology, University of Lund, Sweden.

${ }^{6}$ Corresponding authors, equal contribution

*To whom correspondence should be addressed: Email: claus.nerlov@imm.ox.ac.uk or sten.jacobsen@imm.ox.ac.uk.

Manuscript Correspondence to:

Claus Nerlov, Ph.D.

MRC Molecular Hematology Unit

Weatherall Institute of Molecular Medicine

University of Oxford

John Radcliffe Hospital

Headington

Oxford OX3 9DS

United Kingdom

Phone: +44 1865222324

Fax: +44 1865222500

Email: claus.nerlov@imm.ox.ac.uk 


\begin{abstract}
.
According to current models for hematopoiesis, lymphoid-primed multi-potent progenitors (LMPPs; Lin ${ }^{-} \mathrm{Sca}-1^{+}$c-Kit ${ }^{+} \mathrm{CD}^{+} 4^{+} \mathrm{Flt3}^{\mathrm{hi}}$ ) and common myeloid progenitors (CMPs; Lin ${ }^{-} \mathrm{Sca}-$ $1^{+} \mathrm{c}-\mathrm{Kit}^{+} \mathrm{CD} 34^{+} \mathrm{CD} 41^{\mathrm{hi}}$ ) establish an early branch point for separate lineage commitment pathways from hematopoietic stem cells, with the notable exception that both pathways are proposed to generate all myeloid innate immune cell types through the same myeloidrestricted pre-granulocyte-macrophage progenitor (pre-GM; Lin $^{-} \mathrm{Sca}-1^{-} \mathrm{c}_{-\mathrm{Kit}}^{+} \mathrm{CD}^{-}$ Fc $\gamma \mathrm{RII} / \mathrm{III}^{-} \mathrm{CD}^{-} 5^{-} \mathrm{CD}^{-} 5^{-}$). By single cell transcriptome profiling of pre-GMs we identify distinct myeloid differentiation pathways: a Gata1-expressing pathway generates mast cells, eosinophils, megakaryocytes and erythroid cells, and a Gata1-negative pathway that generates monocytes, neutrophils and lymphocytes. These results identify an early hematopoietic lineage bifurcation, separating the myeloid lineages prior to their segregation from other hematopoietic lineage potentials.
\end{abstract}

\title{
Introduction.
}

The cell types of the myeloid innate immune system, neutrophils, macrophages, eosinophils, mast cells and basophils, each make a unique contribution to immunity against bacteria and parasites ${ }^{1}$. All of these cell types are generated from multi-potent hematopoietic stem cells (HSCs) in a process controlled by a complex network of transcription factors ${ }^{2}$ and extrinsic signals ${ }^{3}$. Knowledge of the cellular pathways by which hematopoietic cell types are generated, and how their production is regulated by infectious organisms and cytokines, is critical to understanding how the immune system functions, and how its dysfunction results in immune cell deficiency or overproduction under pathological conditions ${ }^{4,5}$. Notably, current models for hematopoiesis commonly imply that all myeloid cell types develop from the same granulocyte-macrophage progenitor populations (pre-GM and GMP (defined as $\mathrm{Lin}^{-} \mathrm{Sca}-1^{-} \mathrm{c}-\mathrm{Kit}^{+} \mathrm{CD} 41^{-} \mathrm{Fc} \gamma \mathrm{RII} / \mathrm{III}^{+}$)) ${ }^{2,}$ 6, 7, 8, ${ }^{9}$, which according to the CMP-LMPP hematopoietic model are produced by both the CMP (which is able to generate myeloid cells, megakaryocytes and erythroid cells, but lacks lymphoid lineage potentials $^{10,11}$ ) and LMPP branch (which can generate myeloid and lymphoid cell types, but, lacks megakaryocyte-erythroid lineage potentials ${ }^{12}$ ). Previous studies have shown that GMPs possess combined monocyte-macrophage and neutrophil potential at the clonal level ${ }^{6,10}$. However, granulocytes also include functionally distinct mast cells, basophils and eosinophils, each 
specified through the action of critical transcription factors ${ }^{13}$, and the presence of these potentials in GMPs has so far not been systematically analyzed. It therefore remains an open question if the LMPP and CMP pathways generate the same complement of myeloid cell types.

We here use global gene profiling of single pre-GMs to identify molecularly distinct pre-GM subsets defined by differential expression of Gatal and Flt3, encoding the GATA-1 transcription factor and the Fms-like tyrosine kinase like 3 receptor, respectively. Gatal is of particular interest, as, in addition to its critical role in megakaryocyte and erythrocyte development ${ }^{14,15}$, GATA-1 is expressed in eosinophils, basophils and mast cells (but not monocytes-macrophages and neutrophils), and is important for their differentiation ${ }^{16,17,18}$. By generating Gatal-EGFP reporter mice we were able to fractionate myeloid progenitors based on their Gatal expression, and identify sub-populations that harbored distinct myeloid lineage potentials: Gatal-EGFP ${ }^{+}$ (henceforth $\mathrm{GE}^{+}$) pre-GMs and $\mathrm{GE}^{+}$GMPs gave rise to mast cells and eosinophils, but lacked monocyte-macrophage and had little or no neutrophil potential. Conversely, Gatal-EGFP ${ }^{-}\left(\mathrm{GE}^{-}\right)$ pre-GMs and GE ${ }^{-}$GMPs (as well as LMPPs) generated monocytes and neutrophils, but no mast cells and few eosinophils. Notably, monocyte-neutrophil and mast cell-eosinophil potentials segregated prior to separation from other blood lineages, as $\mathrm{GE}^{+}$pre-GMs generated megakaryocytes and erythroid cells, whereas LMPPs contained robust B- and T-lineage potential.

Our findings therefore identify an early blood lineage fate decision segregating lymphoidmacrophage-neutrophil potential from mast cell-eosinophil-megakaryocytic-erythroid potential, establishing separate myeloid-erythroid and myelo-lymphoid differentiation pathways, and generating two distinct myeloid-restricted progenitor subsets, instead of a common GMP harboring all monocyte-macrophage and granulocyte potentials.

\section{Results}

\section{Single cell RNA sequencing identifies pre-GM heterogeneity}

To address if the same myeloid differentiation pathways emerge from CMPs and LMPPs we performed global single cell gene profiling of bone marrow (BM) pre-GMs ${ }^{6}$, the earliest progenitor predicted to be shared between the two pathways ${ }^{6,7,8}$. RNA sequencing of 63 single pre-GMs was followed by unsupervised clustering using the 100 genes with greatest variance across the entire cell population. This led to the identification of two distinct pre-GM clusters (Supplementary Fig. 1a), and 55 genes showing differential expression between them $(\mathrm{P}<0.05$; 
FDR $<0.05$; Supplementary Fig. 1b) as potential sub-population classifiers. Clustering using this gene set identified three distinct pre-GM subpopulations $\left(\right.$ Gatal $^{+} \mathrm{Flt3}^{-}, \mathrm{Gatal}^{-} \mathrm{Flt}^{-}$and $\mathrm{Gatal}^{-}$ $\mathrm{Flt}^{+}$) defined by expression of Gatal and Flt3 (Fig. 1a), a pattern that was validated by targeted single cell gene expression analysis (Fig. 1b). This analysis also identified Gatal expression as an optimal classifier, homogeneously and selectively expressed in a distinct subpopulation of Flt3 preGMs, but not detected in Flt3 $3^{+}$preGMs. Notably, Gatal and Flt3 expression have been used to define CMPs ${ }^{11}$ and LMPPs $^{12}$, respectively, within the CD34 ${ }^{+}$LSK population, suggesting they have the potential to identify pre-GM subsets derived from these distinct upstream progenitors.

\section{Gata1 expression defines distinct myeloid progenitors}

The Gatal-EGFP transgene used to define $\mathrm{CMPs}^{11}$ lacks key regulatory elements ${ }^{19,20,21}$, and is not expressed in GMPs ${ }^{22}$. We therefore generated the Gatal-EGFP reporter mouse line using a BAC transgenic construct containing all known Gatal regulatory sequences, in which an enhanced green fluorescence protein (EGFP) expression cassette replaced the coding part of the second exon of the Gatal gene (Supplementary Fig. 1c). In these Gatal-EGFP reporter mice distinct $\mathrm{GE}^{+}$and $\mathrm{GE}^{-}$subsets were observed in pre-GMs and GMPs (Fig. 1c; Supplementary Fig. 1d). Within the BM multi-potent $\mathrm{Lin}^{-} \mathrm{Sca}-{ }^{+}{ }^{+} \mathrm{c}-\mathrm{Kit}^{+}$(LSK) compartment, HSCs are CD $150^{+} \mathrm{LSK}^{23}$, whereas LMPPs are Flt3 ${ }^{\text {hi }} \mathrm{LSK}^{12}$. CD $150^{+} \mathrm{LSK}$ cells contained a significant fraction of $\mathrm{GE}^{+}$cells (Fig. 1e; Supplementary Fig. 1e), but only $\mathrm{GE}^{-} \mathrm{CD}_{150^{+} \mathrm{LSK}}$ cells possessed HSC function in vivo (Supplementary Fig. 2a-d). HSCs are therefore defined herein as CD150 ${ }^{+} \mathrm{GE}^{-} \mathrm{LSKs}$. Similarly, a small fraction (2-3\%) of LMPPs had low Gatal-EGFP expression (Fig. 1d). Previous studies showed that approximately $2 \%$ of LMPPs possess detectable Mk potential ${ }^{12}$, and we found this Mk potential to be confined to the small $\mathrm{GE}^{+}$sub-fraction of Flt $3{ }^{\text {hi }}$ LSK cells (Supplementary Fig. 2e), supporting the existence of an LMPP population devoid of platelet-forming capacity ${ }^{12,24}$ ${ }^{25}$, and leading us to stringently define and to sort LMPPs as Flt ${ }^{\text {hi }} \mathrm{GE}^{-}$LSK in this study. Importantly, Gatal-EGFP expression mirrored endogenous Gatal mRNA expression both at the population level (Fig. 1e) and in analysis of single pre-GMs (Supplementary Fig. 2f).

\section{Early separation of macrophage and mast cell potentials}

Quantitative PCR of lineage-specific gene expression showed that megakaryocyte-erythroidaffiliated genes (Itga2b, Klf1, Epor, Gata2) were expressed preferentially in $\mathrm{GE}^{+}$preGMs and GMPs, preMegEs ( $\left.\mathrm{Lin}^{-} \mathrm{Sca}-1^{-} \mathrm{c}-\mathrm{Kit}^{+} \mathrm{CD} 41^{-} \mathrm{Fc} \gamma \mathrm{RII} / \mathrm{III}^{-} \mathrm{CD} 150^{+} \mathrm{CD} 105^{-}\right)$, MkPs $\left(\mathrm{Lin}^{-} \mathrm{Sca}-1^{-} \mathrm{c}-\right.$ 
$\mathrm{Kit}^{+} \mathrm{CD} 41^{+}$) and preCFU-Es ( $\mathrm{Lin}^{-} \mathrm{Sca}-1^{-} \mathrm{c}-\mathrm{Kit}^{+} \mathrm{CD} 41^{-} \mathrm{Fc} \gamma \mathrm{RII} / \mathrm{III}{ }^{-} \mathrm{CD} 150^{+} \mathrm{CD} 105^{+}$) stem/progenitor cell populations (Fig. 1f), as were mast cell genes (Cmal, Mcpt1; Fig. 1g), whereas macrophage (Cd68, Emr1; Fig. 1h), neutrophil (Csf3r, Ctsg; Fig 1i) and lymphoid genes (Rag1, Cmah; Fig. 1j) were selectively expressed in LMPPs, GE ${ }^{-}$pre-GMs and $\mathrm{GE}^{-}$GMPs. The divergent expression of macrophage-neutrophil and mast cell genes between $\mathrm{GE}^{+}$pre-GMs and GMPs and GE ${ }^{-}$pre-GMs and GMPs, suggested that these progenitors could generate different myeloid cell types. We therefore cultured $\mathrm{GE}^{+}$pre-GMs and $\mathrm{GE}^{-}$pre-GMs under pan-myeloid conditions (IL-3, IL-5, IL9, SCF and GM-CSF) for 8 days, and examined the resulting cultures by cytospin morphology and gene expression analysis. Morphological analysis showed that LMPPs and $\mathrm{GE}^{-}$pre-GMs generated monocytes, but no mast cells, whereas $\mathrm{GE}^{+}$pre-GMs generated mast cells, but no monocytes (Fig. 1k). Polymorphonuclear (PMN) cells were observed in both cultures, with neutrophil morphology (small cell size, highly condensed and segmented nucleus) evident in those derived from $\mathrm{GE}^{-}$preGMs and LMPPs, whereas those derived from $\mathrm{GE}^{+}$pre-GMs were generally larger with less condensed nuclei (Fig. 1k). Consistent with the observed separation of mast cell and monocyte-macrophage potential, mast cell-specific genes were exclusively expressed in the $\mathrm{GE}^{+}$pre-GM-derived cultures (Fig 2a), and monocyte-macrophage-specific genes selectively in those derived from LMPPs and $\mathrm{GE}^{-}$pre-GMs (Fig. 2b). Finally, while the genes encoding the myeloid PU.1 and C/EBP $\alpha$ transcription factors were expressed in all cultures, Gata1 and Gata2 expression was confined to cultures derived from $\mathrm{GE}^{+}$pre-GMs (Fig. 2c,d).

To determine the frequencies and distribution of granulocyte and monocyte-macrophage lineage potentials within the different progenitor populations at the single cell level we individually cultured sorted progenitor cells and analyzed their myeloid lineage output at several time points. While single LMPPs, GE ${ }^{-}$pre-GM and $\mathrm{GE}^{-}$GMPs produced large numbers of monocytes, mast cell potential was never detected in cultures of single LMPPs or GE ${ }^{-}$GMPs, and was very rare $\left(<2 \%\right.$ of cultures) in $\mathrm{GE}^{-}$pre-GMs single cell-derived cultures, at all time points investigated. In contrast, monocytes were generated only very rarely, whereas mast cell potential was highly abundant, from $\mathrm{GE}^{+}$pre-GM or $\mathrm{GE}^{+}$GMPs ( $<2 \%$ of single cell cultures) (Fig. 2e), Combined monocyte and mast cell morphology was exceptionally rare, seen only in 2 of $>1000$ single cellderived clones of all progenitor analyzed. Importantly, this was not due to any inability of the culture system to support development of these two cell types simultaneously, as culture of multipotent $\mathrm{HSCs}$ or co-culture of $\mathrm{GE}^{+}$and $\mathrm{GE}^{-}$pre-GMs generated combined mast cells and 
monocytes with high frequency (Supplementary Fig. 2g,h). Both monocytes and mast cells were observed in conjunction with other granulocytes with high frequency in single cell-derived clones from $\mathrm{GE}^{+}$pre-GM cells (22-33\%), GE ${ }^{-}$pre-GM (ca. 50\%) and LMPPs (65\%), and also in GE GMPs and $\mathrm{GE}^{-}$GMPs at lower frequencies (Fig. 2e). The polymorphonuclear cells associated with monocytes showed neutrophil morphology, whereas those associated with mast cells appeared larger with less condensed nuclei (Fig. 2f). These results show that $\mathrm{GE}^{+}$and $\mathrm{GE}^{-}$ myeloid progenitors have distinct lineage potentials.

\section{Eosinophil potential is found in $\mathrm{GE}^{+}$preGMs and GE+ GMPs}

While the above data clearly showed that mast cell and monocyte-macrophage potentials were separated prior to the formation of pre-GMs and GMPs, the nature of the additional granulocyte lineage potentials associated with these progenitors remained unclear. To address this issue we performed Affymetrix-based global gene profiling of pre-GMs, GMPs, HSCs, LMPPs, CLPs $\left(\mathrm{Lin}^{-} \mathrm{B} 220^{-} \mathrm{Sca}-1^{1 \mathrm{lo}} \mathrm{c}-\mathrm{Kit}^{1 \mathrm{lo}} \mathrm{Flt3} 3^{+} \mathrm{IL}-7 \mathrm{R} \alpha^{+}\right)^{26}$ and preMegEs. Consistent with their similar granulocytemonocyte lineage readouts, LMPPs, $\mathrm{GE}^{-}$pre-GMs and $\mathrm{GE}^{-}$GMPs clustered together in principal component analysis, in close association with CLPs, whereas $\mathrm{GE}^{+}$pre-GMs and $\mathrm{GE}^{+} \mathrm{GMPs}$ formed a separate cluster, associated with preMegEs (Fig. 3a). Direct comparison of $\mathrm{GE}^{+} \mathrm{GMPs}$ and $\mathrm{GE}^{-}$GMP transcriptomes showed that $\mathrm{GE}^{+}$GMPs were highly enriched for mast cell and eosinophil-specific gene expression, whereas numerous monocyte-macrophage and neutrophilassociated genes were more highly expressed in GE GMPs (Supplementary Dataset 1). We therefore examined the possibility that the polymorphonuclear cells derived from $\mathrm{GE}^{+}$pre-GMs and $\mathrm{GE}^{+}$GMPs were eosinophils. First, we cultured $\mathrm{GE}^{+}$GMPs and $\mathrm{GE}^{-}$GMPs in the presence of SCF and IL-5 (Supplementary Fig. 3a), and examined the resulting cultures by morphology and gene expression. Under these conditions $\mathrm{GE}^{+}$GMPs did not generate mast cells, but only large polymorphonuclear cells with uncondensed nuclear morphology, while GE ${ }^{-}$GMPs generated cells with monocyte and neutrophil morphology (Fig. 3b). Gene expression analysis indicated the selective expression of eosinophil-specific genes (Il5ra, Ccr3, Siglec5, Prg2) in $\mathrm{GE}^{+} \mathrm{GMP}$ cultures (Fig. 3c), and of monocyte-macrophage-specific genes (Cd68, Lpl, Lrpl, Mpegl) in GE GMP cultures (Fig. 3d). In both cases the cell-type specificity of gene expression was validated by analysis of macrophages and eosinophils sorted from the peritoneal cavity as controls. Cytospins indicated that the morphology of the in vitro (what progenitor)-derived eosinophil-like cells was 
similar to that of purified peritoneal eosinophils (Supplementary Fig. 3b). These results indicated the selective development of eosinophils from $\mathrm{GE}^{+}$GMPs.

We also performed flow cytometric analysis of the cells differentiated from $\mathrm{GE}^{+}$pre-GMs and $\mathrm{GE}^{-}$pre-GMs, as well as $\mathrm{GE}^{+}$GMPs and $\mathrm{GE}^{-}$GMPs following culture under pan-myeloid cytokine conditions. Cells with a FceRI $\alpha^{+} \mathrm{c}-\mathrm{Kit}^{+} \mathrm{GE}^{+}$mast cell surface phenotype were abundant in $\mathrm{GE}^{+}$pre-GM and $\mathrm{GE}^{+}$GMP cultures, whereas Mac- ${ }^{+}$Ly $6 \mathrm{G}^{\mathrm{lo}} \mathrm{GE}^{-}$monocytes and Mac$1^{+} \mathrm{Ly} 6 \mathrm{G}^{\mathrm{hi}} \mathrm{GE}^{-}$neutrophils were the principal cell types generated from $\mathrm{GE}^{-}$pre-GMs and $\mathrm{GE}^{-}$ GMPs (Fig. 4a,b), indicating that neutrophil potential was selectively associated with $\mathrm{GE}^{-}$preGMs and GE ${ }^{-}$GMPs. Eosinophil, neutrophil and mast cell identities were further confirmed by analysis of the expression of lineage-specific genes (Supplementary Fig. 3c-f). FceRI $\alpha^{-}{ }^{-}-K^{-}{ }^{-}$ SiglecF ${ }^{+} \mathrm{GE}^{+}$eosinophils were inefficiently generated under the pan-myeloid conditions (Fig. 4a,b), likely because of overgrowth by mast cells. To circumvent this, we cultured GMP in the presence of IL-5 and SCF, and observed the selective development of eosinophil-like cells in GE ${ }^{+}$ GMP cultures, while $\mathrm{GE}^{-}$GMPs gave rise to monocytes and neutrophils, but few or no eosinophils, even under conditions favoring eosinophil development (Fig. 4c). As such, based on analyses of morphology, surface markers and gene expression we concluded that $\mathrm{GE}^{+}$GMPs gave rise to eosinophils and mast cells, but did not produce detectable neutrophils or monocytes. Finally, to accurately co-localize lineage potentials in single progenitors we combined morphological analysis of cytospins of single cell-derived cultures with immunocytochemistry against EGFP to distinguish $\mathrm{GE}^{+}$eosinophils from $\mathrm{GE}^{-}$neutrophils (Fig. 4d). $G E^{+}$pre-GMs and $\mathrm{GE}^{+}$GMPs contained a high proportion of bi-potent mast cell-eosinophil progenitors, whereas $\mathrm{GE}^{-}$LMPPs, GE ${ }^{-}$pre-GMs and $\mathrm{GE}^{-}$GMPs were abundant in bi-potent neutrophil-monocyte progenitors (Fig. 4e). In addition, under pan-myeloid conditions LMPPs, GE ${ }^{+}$pre-GMs and GE pre-GMs we observed the emergence of $\mathrm{Fc} \gamma \mathrm{RII} / \mathrm{III}^{+} \mathrm{GE}^{+}$cells from $\mathrm{GE}^{+}$pre-GMs and Fc $\gamma \mathrm{RII} / \mathrm{III}^{+} \mathrm{GE}^{-}$cells from $\mathrm{GE}^{-}$pre-GMs and LMPPs in both cases displaying the clonogenic lineage potentials of the corresponding $\mathrm{GE}^{+}$and $\mathrm{GE}^{-}$GMP population (Supplementary Fig. 4a,b), further supporting the existence of independent and functionally distinct $\mathrm{GE}^{+}$and $\mathrm{GE}^{-}$ progenitor hierarchies. The comparison of gene expression profiles of $\mathrm{GE}^{+} \mathrm{GMPs}_{\mathrm{s}}$ and $\mathrm{GE}^{-} \mathrm{GMPs}$ identified genes encoding cell surface markers that were preferentially expressed in the $\mathrm{GE}^{+}$ 
subsets, such as Cd55, Illrll, or the GE ${ }^{-}$subsets, such as Ly6c (Supplementary Dataset 1). While cell surface expression of I11r11 was not detectable on pre-GMs or GMPs with available antibodies, CD55 and Ly6C were expressed selectively on $\mathrm{GE}^{+}$pre-GMs and GMPs, and GE ${ }^{-}$preGMs and GMPs, respectively (Supplementary Fig. 4c). In agreement with this selective expression, they allowed the separation of progenitors with a restricted monocyte-neutrophil potential $\left(\mathrm{Ly}_{6 \mathrm{C}}{ }^{+}\right.$pre-GMs and GMPs) or restricted mast cell-eosinophil potential $\left(\mathrm{CD} 55^{+}\right.$preGMs and GMPs), without the use of the Gatal-EGFP transgene (Supplementary Fig. 4d). Overall, these results indicate that mast cell-eosinophil potential is found in $\mathrm{GE}^{+}$preGMs and $\mathrm{GE}^{+}$ GMPs, whereas monocyte-neutrophil potential resides in LMPPs, $\mathrm{GE}^{-}$preGMs and $\mathrm{GE}^{-} \mathrm{GMPs}$.

\section{Gata1 expression defines two progenitor domains}

We further examined the extent to which the identified progenitors possessed other lineage potentials. Gene Set Enrichment Analysis-based ${ }^{27}$ comparison of lineage programming in - preGMs and $G E^{+}$pre-GMs showed strong enrichment of Mk-E-associated genes in $\mathrm{GE}^{+}$pre-GMs, and of lymphoid genes in $\mathrm{GE}^{-}$pre-GMs (Fig. 5a). All the identified pre-GM and GMP populations generated colonies when cultured under myeloid conditions (Fig. 5b). In contrast, megakaryocytic and erythroid colony forming ability was primarily associated with $\mathrm{GE}^{+}$pre-GMs, which showed a Mk-E potential comparable to that seen in preMegEs (Fig. 5c,d), and contained multi-potent cells with combined granulocyte and Mk-E potential, but no monocyte-macrophage potential (Fig. 5e,f). Conversely, B- and T-lymphoid potential was high in LMPPs, but also significant in $\mathrm{GE}^{-}$pre-GMs, but not $\mathrm{GE}^{+}$pre-GMs (Fig. 5g; Supplementary Fig. 4e).

Antagonistic transcription factor pairs, including PU.1-GATA-1 and C/EBP-FOG-1, have been proposed to be co-expressed in multi- or bi-potent progenitors, and resolution of the antagonism to underlie lineage bifurcations ${ }^{28}$. We therefore measured the expression of these and other key transcription factors in $\mathrm{GE}^{+}$pre-GMs and GMPs, as well as $\mathrm{GE}^{-}$pre-GMs and GMPs, as well as in HSCs, LMPPs, pre-CFU-Es, pre-MegEs and CLPs, to determine if their expression was consistent with the associated lineage potentials. Most notably, Cebpa, Cebpb and Zfpml (encoding FOG-1) were all expressed in $\mathrm{GE}^{+}$pre-GMs, with Zfpml down-regulated and Cebpa and Cebpb upregulated in $\mathrm{GE}^{+}$GMPs, The converse change, Zfpml upregulation and Cebpa and Cebpb downregulation, was seen in pre-MegEs. The FOG-1 target gene Trib2 ${ }^{29}$, which mediates C/EBP $\alpha$ and $\mathrm{C} / \mathrm{EBP} \beta$ degradation $^{30,31}$, was up-regulated in preMegEs, consistent with their proposed role 
in resolving the multi-potency of $\mathrm{GE}^{+}$pre- $\mathrm{GMs}^{29}$, and with the observed ability of FOG-1 to suppress eosinophil and mast cell lineage differentiation ${ }^{32,33}$. Sfpil (encoding PU.1) and Gatal were expressed in $\mathrm{GE}^{+}$pre-GMs, with Sfpil down-regulated in Mk-E-committed pre-MegEs. Gatal and Sfpil were co-expressed in $\mathrm{GE}^{+}$GMPs, indicating that down-regulation of GATA-1 is not decisive for commitment of $\mathrm{GE}^{+}$pre-GMs to granulocyte lineages, and consistent with PU.1 being required for mast cell differentiation ${ }^{34}$. Finally, key transcriptional regulators of monocytemacrophage $(\operatorname{Irf} 8, K l f 4)^{35}$ and neutrophil $(G f i l)^{36}$ differentiation were highly expressed in LMPP and $\mathrm{GE}^{-}$pre-GM and GMP populations compared to $\mathrm{GE}^{+}$pre-GMs and GMPs (Fig. 6). These data identify LMPPs and GE+ preGMs as distinct multi-potent progenitors with non-overlapping lineage potentials, the former producing lymphocytes, neutrophils and monocuytes-macrophages, and the latter erythrocytes, platelets, eosinophils and mast cells.

\section{Functional heterogeneity of $\mathrm{GE}^{-}$pre-GMs}

Lymphoid lineage potential has been associated with $\mathrm{Flt}^{+}$pre- $\mathrm{GM}^{37}$. By flow cytometry we observed that Flt3 ${ }^{+}$pre-GMs were exclusively GE ${ }^{-}$(Fig. 7a). The selective presence of lymphoid potential in Flt3 ${ }^{+} \mathrm{GE}^{-}$pre-GMs, but not $\mathrm{Flt}^{-} \mathrm{GE}^{-}$pre-GMs raised the possibility that other lineage potentials also differed between these two populations. Bulk and single cell cultures showed that both Flt3 ${ }^{+}$and Flt3 ${ }^{-}$GE $^{-}$pre-GMs generated monocytes and neutrophils (Fig. 7b,c), with the Flt3 $\mathrm{GE}^{-}$pre-GMs perhaps more biased towards neutrophil production. While mast cells did not develop from either progenitor population, a small number of eosinophils developed in the bulk GE $^{-}$Flt3 $^{-}$pre-GM cultures (Fig. 7b), and 7\% of clones derived from single GE $^{-}$Flt3 $^{-}$pre-GMs showed combined neutrophil and eosinophil morphology (Fig. 7c). These results indicate that a minor, but distinct fraction of $\mathrm{GE}^{-} \mathrm{Flt3}^{-}$pre-GM progenitor are restricted to neutrophil and eosinophil differentiation. qRT-PCR profiling of single pre-GMs confirmed expression of Gata1 in GE+ preGMs and of Flt3, with Sfpil mRNA expression being similar across the 3 pre-GM subsets (Fig. 7d-f), consistent with their myeloid progenitor identity. Mk-E and mast lineagespecific genes were co-expressed in $>90 \%$ of single $\mathrm{GE}^{+}$pre-GMs and antagonistic transcription factor pairs, such as Sfpi1-Gata1 and Cebpa-Zfpm 1 were co-expressed with high frequency (32/48 cells and 17/48 cells, respectively) in single $\mathrm{GE}^{+}$pre-GMs, suggesting the molecular properties of multi-potent progenitors. Co-expression of Sfpil-Gatal and Cebpa-Zfpml was not observed in $\mathrm{GE}^{-} \mathrm{Flt3}^{+}$or $\mathrm{GE}^{-} \mathrm{Flt3}^{-}$pre-GMs, which instead had high expression of monocyte-macrophage and neutrophil genes such as $\operatorname{Irf} 8, \operatorname{Csf} 3 r$, consistent with the presence of these lineage potentials in 
both $\mathrm{GE}^{-}$pre-GM sub-populations (Fig. 7g). In addition, the proportion of Flt3 ${ }^{+}$pre-GMs was decreased in Flt3 ligand null mice (Supplementary Fig. 5a,b), suggesting that Flt3 signaling regulates the $\mathrm{Flt}^{+}$pre-GM subset. In contrast, $\mathrm{GE}^{+}$pre-GMs and $\mathrm{GE}^{+}$GMPs were maintained in Gatal $^{f l / Y}$;Mxl-Cre conditional knockout mice after poly(I-C)-induced deletion (Supplementary Fig. 5c,d). Consistent with previous findings ${ }^{38}$, Gatal null $\mathrm{GE}^{+}$progenitors differentiated into mast cells in vitro (Supplementary Fig. 5e,f), possibly due to redundancy with Gata2 in these progenitors. The gene expression of the identified myeloid progenitors is therefore consistent with their observed lineage potentials.

\section{In vivo myeloid potentials of $\mathrm{GE}^{+}$and $\mathrm{GE}^{-}$progenitors}

Finally, we investigated in vivo lineage potentials by co-transplanting Gatal $^{+}$and Gatal $^{-}$ progenitor populations (CD45.2 and CD45.1/2) intrafemorally into non-irradiated, c-Kit hypomorphic $W^{A 1} / W^{A 1}$ recipients (CD45.1) (Supplementary Fig. 6a). Flow cytometry analysis (after 7 and 10-11 days) indicated that $\operatorname{Lin}^{-} \mathrm{CD} 11 \mathrm{~b}^{\mathrm{lo}} \mathrm{Ly} 6 \mathrm{G}^{\mathrm{hi}}$ neutrophils and $\mathrm{Lin}^{-} \mathrm{CD} 11 \mathrm{~b}{ }^{\mathrm{hi}} \mathrm{Ly} 6 \mathrm{G}^{-} \mathrm{c}-$ Kit $^{-}$FceR $1 \alpha^{-}$SiglecF $^{-}$monocytes were generated by Gatal $^{-}$GMPs and GE $^{-}$Flt3 $^{+}$pre-GMs, and

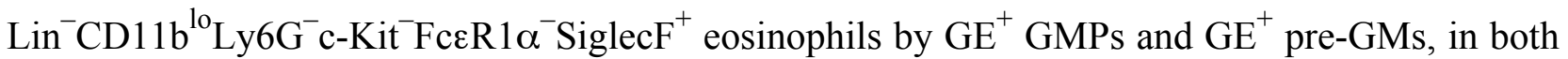
the spleen and bone marrow of reconstituted mice (Fig. 8a and Supplementary Fig. 6b,c). However, overall engraftment levels, in particular of eosinophils, were low, and no Lin ${ }^{-} \mathrm{Ly}_{6 \mathrm{G}^{-} \mathrm{c}-}$ $\mathrm{Kit}^{+}$FceR $1 \alpha^{+}$mast cells were detected. To overcome this obstacle, we tested the ability of GMP and pre-GM progenitors to engraft after intraperitoneal injection, and found that total engraftment of the peritoneum by both pre-GMs and GMPs was 1-2 orders of magnitude higher compared to that observed in bone marrow and spleen after intrafemoral transplant (Supplementary Fig. 6d), and also mast cell development was readily detected (Fig. 8b). Following intraperitoneal transplantation, $\mathrm{GE}^{+}$GMPs generated exclusively peritoneal mast cells and eosinophils, whereas only monocytes and neutrophils were derived from GE ${ }^{-}$GMPs (Fig. 8c). Similarly, $\mathrm{GE}^{+}$pre-GMs produced predominantly mast cells and eosinophils, whereas $\mathrm{GE}^{-} \mathrm{Flt3}{ }^{+}$pre-GMs and LMPPs generated almost exclusively neutrophils and monocytes (Fig. 8d,e). The cellular phenotypes defined by flow cytometry were further validated by morphology (Supplementary Fig. 6e-h) and selective $\mathrm{GE}^{+}$expression in eosinophils and mast cells (Supplementary Fig. 6i). Low numbers of neutrophils (but no monocytes) were produced by $\mathrm{GE}^{+}$pre-GMs, and LMPPs and $\mathrm{GE}^{-} \mathrm{Flt3}^{+}$preGMs generated limited numbers of eosinophils (but no mast cells), indicating that the more 
upstream myeloid progenitors (LMPPs and pre-GMs) retain some lineage plasticity, restricted to the eosinophil and neutrophil lineages in vivo, which is lost in both GE ${ }^{+}$GMP and $\mathrm{GE}^{-}$GMPs (Fig. 8c-e). These results confirmed the same lineage potentials in vivo as observed in vitro for both $\mathrm{GE}^{+}$myeloid progenitors $\left(\mathrm{GE}^{+}\right.$preGMs, $\mathrm{GE}^{+} \mathrm{GMPs}$ ) and $\mathrm{GE}^{-}$progenitors (LMPPs, GE preGMs, $\mathrm{GE}^{-}$GMPs). We therefore propose to designate $\mathrm{GE}^{+}$preGMs as candidate erythroidmegakaryocyte-primed multi-potent progenitors (EMkMPPs), and $\mathrm{GE}^{+}$GMPs as eosinophil-mast cell progenitors (EoMPs). In contrast, since $\mathrm{GE}^{-}$preGMs and $\mathrm{GE}^{-}$GMPs generate predominantly neutrophils and monocytes, we propose to designate them pre-neutrophil-monocyte (preNM) and neutrophil-monocyte progenitors (NMPs), respectively. In different current hematopoietic models all monocyte-macrophage and granuolcyte lineage potentials are proposed to reside in one

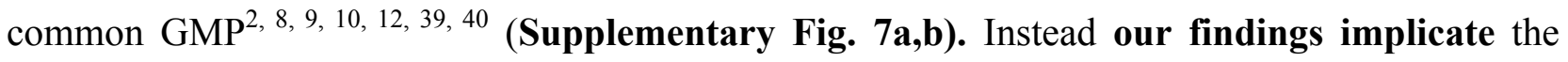
organization of $\mathrm{GE}^{+}$progenitors (EMkMPP, EoMP) and $\mathrm{GE}^{-}$progenitors (LMPP, preNM and NMP) into largely separate hierarchies that generate lymphoid cells, neutrophils and monocytesmacrophages, and eosinophils, mast cells, platelets and erythroid cells, respectively (Supplementary Fig. 7c,d).

\section{Discussion}

We here prospectively isolate and characterize distinct, myeloid progenitor populations restricted to either neutrophil-monocyte (preNM, NMP) or eosinophil-mast cell fate (EoMP), as well as candidate multi-potent progenitors with combined megakaryocyte-erythroid and eosinophil-mast cell potential (EMkMPPs). In addition, we find that LMPPs produce neutrophils and monocytes, but no mast cells and few or no eosinophils.

While existing models imply that segregation of monocyte-macrophage and granulocyte potentials occurs downstream of a common GMP, our results suggest that the separation of Gatalexpressing lineages (megakaryocytes, erythrocytes, eosinophils and mast cells) and Gatal-nonexpressing lineages (lymphocytes, neutrophils, monocytes) represents an early lineage bifurcation of the multi-potent HSCs. These findings substantially change our view of how myeloid cell types are specified, by suggesting that mast cells and eosinophils are generated from an EMkMPP progenitor shared with platelets and erythrocytes, rather than a common GMP. This type of lineage relationship has previously been suggested based on observations of myeloid malignancies $^{41}$. Platelets have important innate immune functions, acting as sentinels and providing chemotaxis of myeloid effector cells ${ }^{42}$, and the platelet-ancestral thrombocyte is capable 
of bacterial phagocytosis ${ }^{43}$. These are all functions shared with mast cells ${ }^{44}$, consistent with mast cells and platelets having evolved through specialization from a common ancestral cell with both hemostatic and phagocytic function. Our results suggest that eosinophils may have evolved from the same GATA-1-expressing hematopoietic branch, possibly as an adaptation to parasites. In contrast, we find that monocytes-macrophages are developmentally closely related to lymphoid cells, as has already been suggested by the identification of progenitors restricted to macrophage and lymphoid differentiation in both fetal $^{45,46,47}$ and adult hematopoiesis ${ }^{48}$.

Recent lineage analysis of myeloid colonies from heterogeneous human CD34+ hematopoietic cells are compatible with a similar separation of human GATA-1 expressing granulocyte lineages along with megakaryocytic and erythroid lineage potentials, with the important distinction that also considerable macrophage potential was observed together with the GATA-1 expressing lineages ${ }^{49}$ This might be related to the investigated human cell populations typically also possessing extensive lymphoid potential of unknown relationship to the investigated granulocyte lineages.

CMPs have been defined as possessing myeloid and megakaryocyte-erythroid lineage potentials, but lacking lymphoid lineage potentials ${ }^{11,50}$, and would potentially generate both preNMs-NMPs and MkEMPPs-EoMPs. However, it has not been established if the CMP population as currently defined ( Lin $\left.^{-} \mathrm{Sca}-1^{+} \mathrm{c}-\mathrm{Kit}^{+} \mathrm{CD} 34^{+} \mathrm{CD} 41^{\mathrm{hi}}\right)^{50}$ contains cells that possess monocyte-macrophage, as well as all granulocyte potentials at the clonal level, and further studies will therefore be required to firmly establish its relationship to the myeloid progenitor populations identified here. In addition, our studies do not preclude that an upstream progenitor with the same lineage potentials as the EMkMPP exists, for instance within the proposed CMP compartment.

In summary, our findings provide an improved cellular and molecular template for elucidating the evolutionary and developmental relationships of hematopoietic cell types, as well as the identification of cells-of-origin of hematopoietic malignancies, and underscore the power of single cell transcriptome analysis to simultaneously resolve cellular heterogeneity and to identify the molecular determinants selectively and uniformly expressed in novel cell subsets, allowing for their purification and functional characterization.

\section{Accession codes.}

The microarray data used in this paper have been deposited in the NCBI GEO database 
(http://www.ncbi.nih.gov/geo) with the accession number GSE49241.

\section{Acknowledgements.}

We thank the EMBL Monterotondo Gene Expression Service and Transgenic Core Facility for generating the Gatal-EGFP BAC and the corresponding transgenic mouse line, and FACS facilities at the ISCR (supported by Wellcome Trust Equipment Grant WT087371MA (C.N.) and WIMM (supported by MRC Grants MC_UU_12009, MC_UU_12025 and G0902418) for flow cytometry and cell sorting. This work was supported by the Medical Research Council, UK Program Grant (H4RPLK0) and Unit Grant (MC_UU_12009/5) (S.E.W.J.), an MRC Strategic Grant (G0701761), Program Grant (G0900892) and Unit Grant (MC_UU_12009/7) (C.N.) and by the European Commission FP7 projects CardioCell (to C.N.) and EuroSyStem (S.E.W.J) projects.

\section{Author contributions.}

C.N., S.E.W.J., R.D., N.B.V., P.W., E.S. and A.M. designed the experiments, R.D., N.B.V., P.W. A.Ga., A.Z., M.L. and A.Gi. performed the experiments, S.T. performed gene expression analysis, E.M. generated the Gatal-EGFP BAC transgenic mouse line, C.N., S.E.W.J. and R.D. wrote the paper.

\section{Competing financial interest statement.}

The authors have no competing financial interests.

\section{References.}

1. Koenderman L, Buurman W, Daha MR. The innate immune response. Immunol Lett 2014, 162(2PB): 95-102.

2. Orkin SH, Zon LI. Hematopoiesis: an evolving paradigm for stem cell biology. Cell 2008, 132(4): 631-644.

3. Metcalf D. Lineage commitment and maturation in hematopoietic cells: the case for extrinsic regulation. Blood 1998, 92(2): 345-347; discussion 352.

4. Sadrzadeh H, Abdel-Wahab O, Fathi AT. Molecular alterations underlying eosinophilic and mast cell malignancies. Discov Med 2011, 12(67): 481-493.

5. Manz MG, Boettcher S. Emergency granulopoiesis. Nat Rev Immunol 2014, 14(5): 302314.

6. Pronk CJ, Rossi DJ, Mansson R, Attema JL, Norddahl GL, Chan CK, et al. Elucidation of the phenotypic, functional, and molecular topography of a myeloerythroid progenitor cell hierarchy. Cell Stem Cell 2007, 1(4): 428-442. 
7. Luc S, Buza-Vidas N, Jacobsen SE. Delineating the cellular pathways of hematopoietic lineage commitment. Semin Immunol 2008, 20(4): 213-220.

8. Iwasaki H, Akashi K. Myeloid lineage commitment from the hematopoietic stem cell. Immunity 2007, 26(6): 726-740.

9. Orkin SH, Zon LI. SnapShot: hematopoiesis. Cell 2008, 132(4): 712.

10. Akashi K, Traver D, Miyamoto T, Weissman IL. A clonogenic common myeloid progenitor that gives rise to all myeloid lineages. Nature 2000, 404(6774): 193-197.

11. Arinobu Y, Mizuno S, Chong Y, Shigematsu H, Iino T, Iwasaki H, et al. Reciprocal activation of GATA-1 and PU.1 marks initial specification of hematopoietic stem cells into myeloerythroid and myelolymphoid lineages. Cell Stem Cell 2007, 1(4): 416-427.

12. Adolfsson J, Mansson R, Buza-Vidas N, Hultquist A, Liuba K, Jensen CT, et al. Identification of Flt3 + lympho-myeloid stem cells lacking erythro-megakaryocytic potential a revised road map for adult blood lineage commitment. Cell 2005, 121(2): 295306.

13. Iwasaki H, Mizuno S, Arinobu Y, Ozawa H, Mori Y, Shigematsu H, et al. The order of expression of transcription factors directs hierarchical specification of hematopoietic lineages. Genes Dev 2006, 20(21): 3010-3021.

14. Fujiwara Y, Browne CP, Cunniff K, Goff SC, Orkin SH. Arrested development of embryonic red cell precursors in mouse embryos lacking transcription factor GATA-1. Proc Natl Acad Sci U S A 1996, 93(22): 12355-12358.

15. Shivdasani RA, Fujiwara Y, McDevitt MA, Orkin SH. A lineage-selective knockout establishes the critical role of transcription factor GATA-1 in megakaryocyte growth and platelet development. Embo J 1997, 16(13): 3965-3973.

16. Yu C, Cantor AB, Yang H, Browne C, Wells RA, Fujiwara Y, et al. Targeted deletion of a high-affinity GATA-binding site in the GATA-1 promoter leads to selective loss of the eosinophil lineage in vivo. J Exp Med 2002, 195(11): 1387-1395.

17. Migliaccio AR, Rana RA, Sanchez M, Lorenzini R, Centurione L, Bianchi L, et al. GATA-1 as a regulator of mast cell differentiation revealed by the phenotype of the GATA-1low mouse mutant. J Exp Med 2003, 197(3): 281-296.

18. Nei Y, Obata-Ninomiya K, Tsutsui H, Ishiwata K, Miyasaka M, Matsumoto K, et al. GATA-1 regulates the generation and function of basophils. Proc Natl Acad Sci U S A 2013, 110(46): 18620-18625.

19. Jasinski M, Keller P, Fujiwara Y, Orkin SH, Bessler M. GATA1-Cre mediates Piga gene inactivation in the erythroid/megakaryocytic lineage and leads to circulating red cells with a partial deficiency in glycosyl phosphatidylinositol-linked proteins (paroxysmal nocturnal hemoglobinuria type II cells). Blood 2001, 98(7): 2248-2255. 
20. Drissen R, Guyot B, Zhang L, Atzberger A, Sloane-Stanley J, Wood B, et al. Lineagespecific combinatorial action of enhancers regulates mouse erythroid Gatal expression. Blood 2010, 115(17): 3463-3471.

21. Suzuki M, Moriguchi T, Ohneda K, Yamamoto M. Differential contribution of the Gata1 gene hematopoietic enhancer to erythroid differentiation. Mol Cell Biol 2009, 29(5): $1163-1175$.

22. Iwasaki H, Mizuno S, Mayfield R, Shigematsu H, Arinobu Y, Seed B, et al. Identification of eosinophil lineage-committed progenitors in the murine bone marrow. J Exp Med 2005, 201(12): 1891-1897.

23. Kiel MJ, Yilmaz OH, Iwashita T, Yilmaz OH, Terhorst C, Morrison SJ. SLAM family receptors distinguish hematopoietic stem and progenitor cells and reveal endothelial niches for stem cells. Cell 2005, 121(7): 1109-1121.

24. Forsberg EC, Serwold T, Kogan S, Weissman IL, Passegue E. New evidence supporting megakaryocyte-erythrocyte potential of flk $2 / \mathrm{flt} 3+$ multipotent hematopoietic progenitors. Cell 2006, 126(2): 415-426.

25. Luc S, Anderson K, Kharazi S, Buza-Vidas N, Boiers C, Jensen CT, et al. Downregulation of $\mathrm{Mpl}$ marks the transition to lymphoid-primed multipotent progenitors with gradual loss of granulocyte-monocyte potential. Blood 2008, 111(7): 3424-3434.

26. Luc S, Luis TC, Boukarabila H, Macaulay IC, Buza-Vidas N, Bouriez-Jones T, et al. The earliest thymic $\mathrm{T}$ cell progenitors sustain $\mathrm{B}$ cell and myeloid lineage potential. Nat Immunol 2012, 13(4): 412-419.

27. Subramanian A, Tamayo P, Mootha VK, Mukherjee S, Ebert BL, Gillette MA, et al. Gene set enrichment analysis: a knowledge-based approach for interpreting genome-wide expression profiles. Proc Natl Acad Sci U S A 2005, 102(43): 15545-15550.

28. Orkin SH. Diversification of haematopoietic stem cells to specific lineages. Nat Rev Genet 2000, 1(1): 57-64.

29. Mancini E, Sanjuan-Pla A, Luciani L, Moore S, Grover A, Zay A, et al. FOG-1 and GATA-1 act sequentially to specify definitive megakaryocytic and erythroid progenitors. Embo J 2012, 31(2): 351-365.

30. Keeshan K, He Y, Wouters BJ, Shestova O, Xu L, Sai H, et al. Tribbles homolog 2 inactivates C/EBPalpha and causes acute myelogenous leukemia. Cancer Cell 2006, 10(5): 401-411.

31. Naiki T, Saijou E, Miyaoka Y, Sekine K, Miyajima A. TRB2, a mouse Tribbles ortholog, suppresses adipocyte differentiation by inhibiting AKT and C/EBPbeta. J Biol Chem 2007, 282(33): 24075-24082.

32. Querfurth E, Schuster M, Kulessa H, Crispino JD, Doderlein G, Orkin SH, et al. Antagonism between C/EBPbeta and FOG in eosinophil lineage commitment of multipotent hematopoietic progenitors. Genes Dev 2000, 14(19): 2515-2525. 
33. Cantor AB, Iwasaki H, Arinobu Y, Moran TB, Shigematsu H, Sullivan MR, et al. Antagonism of FOG-1 and GATA factors in fate choice for the mast cell lineage. $J$ Exp Med 2008, 205(3): 611-624.

34. Walsh JC, DeKoter RP, Lee HJ, Smith ED, Lancki DW, Gurish MF, et al. Cooperative and antagonistic interplay between PU.1 and GATA-2 in the specification of myeloid cell fates. Immunity 2002, 17(5): 665-676.

35. Kurotaki D, Osato N, Nishiyama A, Yamamoto M, Ban T, Sato H, et al. Essential role of the IRF8-KLF4 transcription factor cascade in murine monocyte differentiation. Blood 2013, 121(10): 1839-1849.

36. Hock H, Hamblen MJ, Rooke HM, Traver D, Bronson RT, Cameron S, et al. Intrinsic requirement for zinc finger transcription factor Gfi-1 in neutrophil differentiation. Immunity 2003, 18(1): 109-120.

37. Chi AW, Chavez A, Xu L, Weber BN, Shestova O, Schaffer A, et al. Identification of Flt3CD150 myeloid progenitors in adult mouse bone marrow that harbor $\mathrm{T}$ lymphoid developmental potential. Blood 2011, 118(10): 2723-2732.

38. Ohneda K, Moriguchi T, Ohmori S, Ishijima Y, Satoh H, Philipsen S, et al. Transcription factor GATA1 is dispensable for mast cell differentiation in adult mice. Mol Cell Biol 2014, 34(10): 1812-1826.

39. Kondo M, Weissman IL, Akashi K. Identification of clonogenic common lymphoid progenitors in mouse bone marrow. Cell 1997, 91(5): 661-672.

40. Luc S, Buza-Vidas N, Jacobsen SE. Biological and molecular evidence for existence of lymphoid-primed multipotent progenitors. Ann N Y Acad Sci 2007, 1106: 89-94.

41. Arock M, Schneider E, Boissan M, Tricottet V, Dy M. Differentiation of human basophils: an overview of recent advances and pending questions. J Leukoc Biol 2002, 71(4): 557-564.

42. Vieira-de-Abreu A, Campbell RA, Weyrich AS, Zimmerman GA. Platelets: versatile effector cells in hemostasis, inflammation, and the immune continuum. Semin Immunopathol 2012, 34(1): 5-30.

43. Nagasawa T, Nakayasu C, Rieger AM, Barreda DR, Somamoto T, Nakao M. Phagocytosis by Thrombocytes is a Conserved Innate Immune Mechanism in Lower Vertebrates. Front Immunol 2014, 5: 445.

44. Abraham SN, St John AL. Mast cell-orchestrated immunity to pathogens. Nat Rev Immunol 2010, 10(6): 440-452.

45. Cumano A, Paige CJ, Iscove NN, Brady G. Bipotential precursors of B cells and macrophages in murine fetal liver. Nature 1992, 356(6370): 612-615.

46. Lacaud G, Carlsson L, Keller G. Identification of a fetal hematopoietic precursor with B cell, T cell, and macrophage potential. Immunity 1998, 9(6): 827-838. 
47. Kawamoto H, Ohmura K, Katsura Y. Direct evidence for the commitment of hematopoietic stem cells to T, B and myeloid lineages in murine fetal liver. Int Immunol 1997, 9(7): 1011-1019.

48. Montecino-Rodriguez E, Leathers H, Dorshkind K. Bipotential B-macrophage progenitors are present in adult bone marrow. Nat Immunol 2001, 2(1): 83-88.

49. Gorgens A, Radtke S, Mollmann M, Cross M, Durig J, Horn PA, et al. Revision of the human hematopoietic tree: granulocyte subtypes derive from distinct hematopoietic lineages. Cell Rep 2013, 3(5): 1539-1552.

50. Miyawaki K, Arinobu Y, Iwasaki H, Kohno K, Tsuzuki H, Iino T, et al. CD41 marks the initial myelo-erythroid lineage specification in adult mouse hematopoiesis: redefinition of murine common myeloid progenitor. Stem Cells 2015, 33(3): 976-987. 


\section{Figure legends.}

\section{Figure 1. Gata1 expression identifies distinct myeloid progenitor subsets.}

(a) Hierarchical clustering of single pre-GM cells using the gene set from Supplementary Figure 1b. The major molecularly distinct cell clusters are labeled according to Gatal and Flt3 expression. (b) Heatmap showing expression of genes selectively expressed between the 3 clusters from (a) in single pre-GMs. Expression values were normalized to Hprt expression and shown as deviation from mean expression value of each individual gene. Cells were grouped according to descending Gatal and Flt3 expression. (c) EGFP expression in pre-GM, GMP, preMeg-E, MkP, pre-CFU-E and CFU-E populations from Gatal-EGFP ${ }^{\mathrm{tg} /+}$ adult bone marrow. The percentage of EGFP positive cells is indicated. Gates were set based on wild type cells. Gating strategy for the populations is depicted in Supplementary Figure 1d. (d) EGFP expression in LSKCD $150^{+}$Flt $^{-}$and LSKFlt $3^{\text {hi }}$ cells. Gating strategy for populations is depicted in Supplementary Figure 1e. (e-j) Quantitative PCR analysis of mRNA expression relative to Hprt of Gatal (e), genes associated with megakaryocytes/erythrocytes (f), mast cells (g), monocytesmacrophages (h), neutrophils (i) and lymphoid cells (j) in purified stem- and progenitor populations. (k) Representative morphology of cells from day 8 of cultures of LMPPs, pre-GMs $\mathrm{GE}^{-}$and pre-GMs $\mathrm{GE}^{+}$. Monocytes (Mo), polymorphonuclear granulocytes (PMN), and mast cells $(\mathrm{Ma})$ are indicated. Scale bars: $25 \mu \mathrm{m}$. Analysis representative of 20 (c) and 5 (d) independent experiments is shown. Gene expression is mean \pm s.e.m, $n=3$ biological replicates, except $n=2$ for pre-GM EGFP' $(\mathbf{e}-\mathbf{j})$.

Figure 2. $\mathrm{GE}^{-}$and $\mathrm{GE}^{+}$progenitor cells have distinct myeloid lineage potentials. (a-c) Total cell populations produced from LMPPs, pre-GM GE ${ }^{-}$and pre-GM GE ${ }^{+}$progenitors after 8 days of culture were analyzed by quantitative-PCR for expression of genes associated with mast cells (a), monocytes-macrophages (b) and for myeloid-erythroid transcription factors (c). Gene expression is presented relative to $U b c$ expression. (d) LMPP, pre-GM GE ${ }^{-}$and pre-GM GE populations were cultured for 3 days with mSCF and mIL-3, allowing the cells to reach a GMP stage, as defined by Fc $\gamma$ RII/III expression. Histograms show EGFP expression of in vitro derived Fc $\gamma \mathrm{RII} / \mathrm{III}^{+}$cells from indicated progenitor populations. Percentages of EGFP negative and positive cells are indicated. (e) Cell type analysis by morphology of cytospins from single cell cultured LMPPs, $\mathrm{GE}^{-}$and $\mathrm{GE}^{+}$pre-GMs and GMPs, shown as frequency of analyzed clones (numbers on top of bars). Time of culture is indicated in days. Clones were scored as immature only if no differentiated cell type was found. Mo: monocyte, PMN: Polymorphonuclear granulocytes, Ma: mast cell. (f) Morphology of representative mixed lineage clones from cultured 
single progenitors. Monocytes (Mo), polymorphonuclear granulocytes (PMN), and mast cells (Ma) are indicated. Scale bars: $25 \mu \mathrm{m}$. Gene expression is mean $\pm \mathrm{SD}, n=6$ biological replicates (a,b,c). EGFP expression is mean $\pm \mathrm{SD}, n=2$ and $n=7$ biological replicates for LMPP and preGMs respectively (d). Data from (e) is representative for 6 independent experiments.

\section{Figure 3. Identification of lineage potentials associated with the Gata1-expressing and non-} expressing myeloid pathways. (a) Principal component analysis of hematopoietic stem/progenitor cell populations. Gene expression profiles were generated for each cell population using Affymetrix MoGene 1.0 arrays. Genes differentially expressed across the entire experiment (ANOVA $\mathrm{P}<0.05 ; \mathrm{CV}>0.4 ; 2.305$ genes) were used to calculate the components, and individual expression profiles were plotted against the first 3 components. Clusters containing GATA-1 non-expressing (LMPP, pre-GM GE', GMP GE) and GATA-1-expressing progenitors (pre-Meg-E, pre-GM GE ${ }^{+}$, GMP GE ${ }^{+}$) are highlighted. (b) Morphology of cultures derived from GMP GE (left panel) and GMP GE (right panel) under eosinophil favoring culture conditions as depicted in Supplementary Figure 3a. Images show typical neutrophil morphology (black arrowheads), monocytes (white arrowheads) and polymorphonuclear cells (black arrows). Scale bars: $25 \mu \mathrm{m}$. (c, d) Expression of eosinophil genes (c) and monocyte-macrophage genes (d) in GMP cultures, compared to monocytes (Mo) and eosinophils (Eo) purified from peritoneal cavity. Results are presented relative to Hprt expression (mean $\pm \mathrm{SD})(n=2$ biological replicates, each containing 4 technical replicates). For (a) 4 individual gene expression profiles were made for GMP $\mathrm{GE}^{-}$and LMPP, and 3 for other populations.

Figure 4. Derivation of eosinophils from GMP $\mathrm{GE}^{+}$and neutrophils from GMP GE . (a) FACS analysis of cells produced from GMP $\mathrm{GE}^{-}$and GMP $\mathrm{GE}^{+}$, cultured for 8 days under conditions sustaining all myeloid cell types, identifying monocytes (Mo), neutrophils (Ne), mast cells (Ma) and eosinophils (Eo) with indicated markers. Numbers indicate cells in the gate as percentage of analyzed live single cells. (b) Quantification of identified cell types after 8 day cultures of GMPs and pre-GMs as in (a) shown as percentage of live cells. (c) Quantification of identified cell population as in (a) after culturing GMPs under eosinophil favoring conditions. (d) Immunocytochemistry detecting EGFP expression (brown stain) on cytospins of cultured GE pre-GMs. Monocytes (Mo), neutrophils (Ne), mast cells (Ma) and eosinophils (Eo) are shown. Scale bars: $20 \mu \mathrm{m}$ (e) Morphological analysis after staining for EGFP as in (d) of cytospins from single cell cultured LMPPs, and $\mathrm{GE}^{-}$and $\mathrm{GE}^{+}$pre-GMs and GMPs, cultured for 8 days under pan-myeloid conditions. Cell types are shown as frequency of analyzed clones (numbers on top 
of bars). FACS quantification show data from $n=8$ biological replicates and error bars indicate $\mathrm{SD}(\mathbf{b}, \mathbf{c})$. Data from (e) was accumulated from 3 independent experiments.

Figure 5. Granulocyte-monocyte potentials segregate prior to dissociation from lymphoid and erythro-megakaryocytic lineages.

(a) GSEA-based comparison of $\mathrm{GE}^{-}$and $\mathrm{GE}^{+}$pre-GM gene expression using CLP (top) and preMeg-E (bottom) gene sets. Normalized enrichment score (NES) and P-value are indicated.

(b-e) Colony formation evaluated after 8 days of culture of indicated progenitor cells. Type of colonies assayed are (b) myeloid (CFU-GM), (c) erythroid (BFU-E), (d) megakaryocyte (CFU$\mathrm{Mk}$ ) and (e) combined myeloid and erythroid (CFU-Mix). (f) Cytospins from single CFU-Mix colonies derived from pre-GM GE ${ }^{+}$, showing combined erythroid cells (Ery), polymorphonuclear cells (PMN), megakaryocytes (Meg) and mast cells (Ma) but no monocytes. Scale bars: $25 \mu \mathrm{m}$. (g) Assessment of lymphoid potential of the indicated progenitors. For each population the indicated number of cells/well were plated under B-cell (OP9 stroma) and T-cell (OP9-DL1 stroma) conditions. Bars indicate the percentage of wells producing B-cells (defined as CD19 ${ }^{+}$) (top) or T-cells (defined as Thy $1.2^{+} \mathrm{CD} 25^{+}$or $\mathrm{CD} 4^{+} \mathrm{CD} 8^{+}$) (bottom), respectively. Mean ( \pm s.e.m.) number of positive wells plated with 1, 10 or 50 cells. Data are from 2 experiments each with 24 wells/population and cell density. Number of CFU-GM, BFU-E and CFU-Mk colonies are shown as mean \pm s.e.m of 6,7,6,8,4 (b), 8,7,6,6,4 (c) and 7,7,7,6,4 (d) biological replicates for pre-GM $\mathrm{GE}^{-}$, pre-GM GE ${ }^{+}$, GMP GE ${ }^{-}$GMP GE ${ }^{+}$and pre-Meg-E resp. from 4 experiments. Numbers of CFU-mix colonies are mean \pm SD from 3 biological replicates, each assayed in technical duplicate.

Figure 6. Gene expression in hematopoietic stem/progenitor populations.

Quantitative PCR analysis of mRNAs of indicated genes in hematopoietic stem and progenitor populations as indicated. Data show mRNA expression relative to Hprt. (mean $\pm \mathrm{SD}, n=3$ biological replicates for each population, except $n=2$ for preGM $\mathrm{GE}^{-}$).

\section{Figure 7. Flt3 expression subdivides the pre-GM GE ${ }^{-}$population.}

(a) FACS profiles showing Flt3 and EGFP expression in pre-GMs and GMPs from GatalEGFP $^{\mathrm{tg} /+}$ BM. Numbers indicate percentage of cells within each gate. (b) 100 cells of indicated pre-GMs were grown for 8 days and cell type was analyzed as in Fig. 4a. and shown as percentage of analyzed cells. (c) Single pre-GMs were grown for 8 days under pan-myeloid conditions and cytospins stained as in Fig. 4d. Cell types are shown as percentage of total 
analyzed clones, indicated on top of bars. (d-f) Gatal (d), Flt3 (e) and Spfil (f) expression in single cells of indicated progenitors, shown as mRNA $\left(\log _{2}\right)$, normalized to Hprt and deviated from the mean. Numbers below graphs indicate cells positive for respective gene expression out of total number of cells. (g) Heatmap showing expression of genes including megakaryocyte/erythrocyte (Mk-E), mast cell (Ma) and neutrophil-monocyte (Ne Mo) related genes in single pre-GMs. Values were normalized to Hprt and shown as deviation from mean of each individual gene. FACS plots are representative for 10 independent experiments (a). Percentage of cell type (b) is mean \pm SD from 12 (Pre-GM GE Flt3 $^{+}$and Pre-GM GE Flt3 $^{-}$) and 7 (Pre-GM GE ${ }^{+} \mathrm{Flt}^{-}$) biological replicates from 2 experiments. Analyzed clones (c) are accumulated from 2 independent experiments. Mann-Whitney U-test was used for expression levels (above graphs), Fisher's exact test was used to compare expression frequencies between population (below graphs) $(* \mathrm{p}<0.0001, * * \mathrm{p}=0.001, * * * \mathrm{p}=0.002)(\mathbf{d})$.

\section{Figure 8. in vivo myeloid reconstitution of $\mathrm{GE}^{-}$and $\mathrm{GE}^{+}$myeloid progenitor cells.}

(a) Representative gating strategy for identification of peritoneal neutrophils ( $\mathrm{Ne})$, mast cells (Ma), monocytes (Mo) and eosinophils (Eo). (b) Representative gating strategy for identification of donor derived CD45.1/2 or CD45.2 mast cells (Ma), eosinophils (Eo), neutrophils (Ne) and monocytes (Mo) 7 (GMP) and 11 (pre-GM) days following IP transplantation. Percentages shown are relative to total cells generated from CD45.1/2 and CD45.2 cells, respectively. (c-e) Quantification of in vivo contribution of $\mathrm{GE}^{+}$and $\mathrm{GE}^{-} \mathrm{GMPs}(\mathbf{c}), \mathrm{GE}^{+} \mathrm{Flt3}^{-}$and $\mathrm{GE}^{-} \mathrm{Flt3}^{+}$pre-GMs (d) and LMPPs (e) to peritoneal mast cells, eosinophils, neutrophils and monocytes at indicated days after intraperitoneal transplantation of 1000-4000 cells/donor. Donor derived cells per million analyzed MNCs per 1000 injected cells is shown. * indicates that reconstitution was below detection limit (see methods and Supplementary Fig. 6). 
Online Methods.

\section{Mouse lines}

The Gatal-EGFP transgene was generated by bacterial artificial chromosome recombinant engineering in bacteria at the EMBL Genome Engineering Core Facility (http://www.embl.it/services/genome-engineering-service/index.html). In this transgene an EGFPpolyA cassette replaced the coding part of the second exon of the mouse Gatal gene. Gatal-EGFP mice were generated by intracytoplasmic sperm injection ${ }^{51}$ at the EMBL Monterotondo Transgenic Facility (http://www.embl.it/services/transgenic_facility/index.html). Mice were backcrossed for more than 6 generations onto a C57Bl/6J background. Mice were bred and maintained at the animal facilities of Edinburgh University and Oxford University, UK. Experimental protocols were approved by the Edinburgh University School of Biological Sciences Ethical Review Committee, and the Oxford University Clinical Medicine Ethical Review Committee. Flt3l knockout ${ }^{52}$, Kit $W^{A 1} / W^{A 1}$ (https://www.jax.org/strain/000119), Gatal conditional knockout mice ${ }^{53}$ and $M x 1-C r e$ transgenic mice ${ }^{54}$ were previously generated. All experiments were performed under projects licenses from the UK Home Office. Mice were sacrificed for harvesting hematopoietic cell populations at an age of 6-17 weeks. Both male and female mice were used.

\section{FACS and flow cytometry}

BD LSRFortessa, LSRII, a FACS Aria II, AriaIII and FACSAria Fusion (BD Biosciences) were used for flow cytometry and cell sorting. Cells were prepared for cell sorting by either CD117 enrichment by autoMACS Pro Separator (Miltenyi Biotec) ${ }^{26}$ or lineage depletion using immunomagnetic beads ${ }^{12}$. In stainings where anti-Fc $\gamma$ RII/III antibody was not included, cells were incubated with Fc-block. FlowJo analysis software (TreeStar) was used for subsequent data analysis. Antibodies used are listed below. Populations were defined as follows: HSCs: Lin ${ }^{-}$Sca-

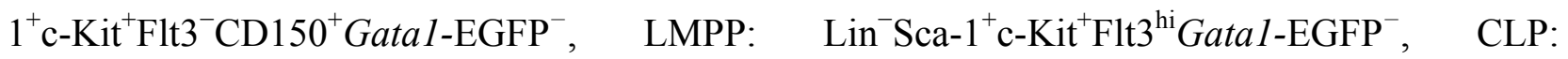

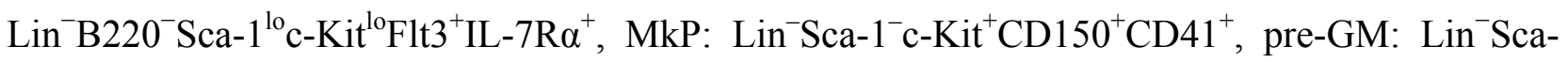
$1^{-} \mathrm{c}-\mathrm{Kit}^{+} \mathrm{CD} 41^{-} \mathrm{Fc} \gamma \mathrm{RII} / \mathrm{III}^{-} \mathrm{CD} 105^{-} \mathrm{CD} 150^{-}, \quad \mathrm{GMP}: \quad \mathrm{Lin}^{-} \mathrm{Scal}^{-} \mathrm{c}-\mathrm{Kit}^{+} \mathrm{CD} 41^{-} \mathrm{CD} 150^{-} \mathrm{Fc} \gamma \mathrm{RII} / \mathrm{III}^{+}$; preMegE: Lin $^{-} \mathrm{Sca}-1^{-} \mathrm{c}-\mathrm{Kit}^{+} \mathrm{CD} 41^{-} \mathrm{Fc} \gamma \mathrm{RII} / \mathrm{III}^{-} \mathrm{CD} 150^{+} \mathrm{CD} 105^{-}$, preCFU-E: Lin $^{-} \mathrm{Sca}-1^{-} \mathrm{c}-\mathrm{Kit}^{+} \mathrm{CD} 41^{-}$

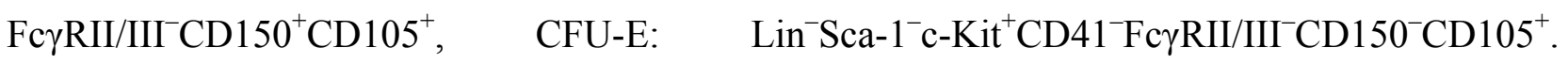
Eosinophils from the peritoneal cavity: Lin(CD4, CD5, CD8, Ter119, B220) ${ }^{-}$CD11b ${ }^{10} \mathrm{Ly}_{6 \mathrm{G}^{-}}$ SiglecF ${ }^{+}$FceR1 $\alpha^{-} \mathrm{F} 4 / 80^{-}$Gatal-EGFP $^{+}$. Macrophages from the peritoneal cavity: Lin(CD4, CD5,

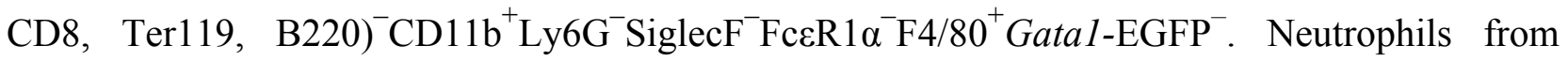
peripheral blood: Lin(CD4, CD5, CD8, Ter119, B220) ${ }^{-} \mathrm{CD} 11 \mathrm{~b}^{\mathrm{lo}} \mathrm{Ly}_{6 \mathrm{G}^{+}}$SiglecF$^{-} \mathrm{Fc} \varepsilon \mathrm{R} 1 \alpha^{-} \mathrm{F} 4 / 80^{-}$. 
See also Transplantation studies.

\section{Transplantation studies}

In order to directly compare the in vivo potential of pre-GM and GMP progenitors subfractionated based on Gatal expression, equal numbers of $\mathrm{GE}^{+}$and $\mathrm{GE}^{-}$cells were co-transplanted competitively into $W^{A 1} / W^{A 1}$ recipient mice (5-10 weeks of age) on a C57B1/6 and CD45.1 background. By utilizing Gatal-EGFP ${ }^{\mathrm{tg} /+}$ mice on a CD45.2 or a mixed CD45.1/2 background, the contribution of the two competitor populations to the myeloid lineages could be separated and distinguished from each other endogenous cells based on CD45 allotype, and directly compared in a single recipient. Briefly, $\mathrm{GE}^{+} \mathrm{GMPs}$ or $\mathrm{GE}^{+} \mathrm{Flt3}^{-}$pre-GMs were sorted from a CD45.2 donor and mixed with equal cell numbers of $\mathrm{GE}^{-}$GMPs or $\mathrm{GE}^{-} \mathrm{Flt3} 3^{+}$pre-GMs, or vice versa. LMPP cells were isolated from either CD45.1/2 or CD45.2 Gatal-EGFP mice. Purified cells were either injected intraperitoneally (I.P.; 1000-4000 cells from each donor) or intra-femorally (I.F.; 200011000 cells from each donor) into $W^{41} / W^{41}$ CD45.1 mice. For I.P. transplantation, recipients were I.P. injected 12-24 hours before transplantation with $1.5 \mathrm{ml}$ of distilled water to deplete endogenous mast cells ${ }^{55}$.

Contribution to the myeloid lineages was assessed by peritoneal lavage 4-20 days postinjections for I.P. injected mice and by analysis of injected femur and spleen 7 and 10 days postinjection for I.F. injected mice. The contribution of CD45.2 and CD45.1/2 donor cells to mast cells, eosinophils, monocytes and neutrophils was assessed by flow cytometry using the following

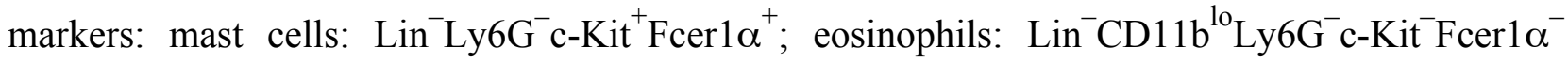

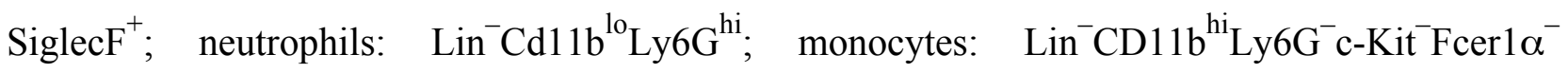
SiglecF ${ }^{-}$. Lin: CD4, CD5, CD8a, CD19, Ter119. The contribution of the individual donors (CD45.2 or CD45.1/2) to each lineage was adjusted to the number of cells injected and number of total mononuclear cells analyzed, and expressed as cells per million mononuclear cells per 1000 transplanted cells analyzed. Average values below 2 events per 1 million cells analyzed per 1000 cells injected were not above the non-specific background, and therefore not used to evaluate lineage-contribution of donor-derived cells.

\section{Gata1 knock out studies}

Chimeric conditional Gatal $^{\mathrm{cKO}}$ mice were established by co-transplanting $0.5 \times 10^{6}$ Gatal $^{\mathrm{cKO}}$ $\left(\right.$ Gatal $^{\mathrm{fl} / \mathrm{y}} \mathrm{Mxl}$-Cre $e^{\mathrm{tg} /+}$ Gatal-EGFP $\left.{ }^{\mathrm{tg} /+}, \mathrm{CD} 45.2\right)$ and $0.5 \times 10^{6}$ wild type bone marrow cells 
(CD45.1) into lethally irradiated CD45.1/2 recipients. For the non-deletion control, Gatal ${ }^{\mathrm{fl} / \mathrm{y}} \mathrm{Mxl}$ $\mathrm{Cre}^{+/+}$Gatal-EGFP $^{\mathrm{tg} /+}, \mathrm{CD} 45.2$ were used. After 6 weeks, engraftment was established by analysis of CD45 allotypes in peripheral blood, and the CD45.2 cells contributed between 30$60 \%$. To induce deletion of the Gatal gene by CRE, mice were treated with $225 \mu \mathrm{g}$ poly(I-C) 8-10 weeks after transplantation by 3 intra-peritoneal injections every other day. Since Gatal is essential for differentiation to erythroid progenitors and erythrocytes ${ }^{29}$, Gatal deletion was confirmed 8-9 weeks after poly(I-C) treatment by absence of CD45.2 CFU-E cells or EGFP signal in erythroid cells.

\section{In vitro cultures}

To test myeloid potential, cells were cultured in IMDM with L-glutamine (Invitrogen), 20\% heat inactivated fetal calf serum (Gibco), penicillin/streptomycin (Invitrogen) and $10^{-4} \mathrm{M} \beta$ mercaptoethanol (Sigma), supplemented with 20ng/ml mSCF (Peprotech), 20ng/ml mIL-3 (Peprotech), 10ng/ml mGM-CSF (Peprotech), 50ng/ml mIL-5 (R\&D Systems) and 50ng/ml mIL-9 (R\&D Systems) at $37^{\circ} \mathrm{C}, 5 \% \mathrm{CO}_{2}$. Bulk cultures of LMPP and pre-GM were started with 10020.000 cells per culture. Myeloid potential of single cells was tested by sorting single cells directly into Terasaki plates, unless stated differently in the text, each well containing $20 \mu 1$ medium. GMP cells were derived in vitro by culturing progenitors (pre-GM or LMPP) for 3 days with $100 \mathrm{ng} / \mathrm{ml}$ $\mathrm{mSCF}$ and 10ng/ml mIl-3 in round bottom 96 well plates and Fc $\gamma \mathrm{RII} / \mathrm{III}^{+}$cells were in this experiment considered as GMPs. In vitro derived GMPs were manually plated at an average of 5 cells/well into 60 well Terasaki plates. For eosinophil favouring culture conditions, GMP cells (200 cells/culture) were grown with $20 \mathrm{ng} / \mathrm{ml} \mathrm{mSCF}, 10 \mathrm{ng} / \mathrm{ml} \mathrm{mGM-CSF}$ and $50 \mathrm{ng} / \mathrm{ml} \mathrm{Il-5} \mathrm{in}$ round bottom 96 well plates. After 5 days, the cells were washed and put back in culture for another 2 days without $\mathrm{mSCF}$ and $\mathrm{mGM-CSF}$. All cytospins were prepared with a Shandon cytospin at 1000 RPM with low acceleration, followed by May-Grünwald-Giemsa stain (VWR).

\section{Immunocytochemistry}

Air dried cytospins were fixed with 4\% PFA in PBS for 5 minutes. Slides were first blocked with PBS/5\%BSA containing Fc-block for 30 min at RT and then with $3 \% \mathrm{H}_{2} \mathrm{O}_{2}$ in water for 5 minutes. Slides were incubated with chicken polyclonal anti-GFP (Abcam, ab13970) in PBS/5\% BSA for 4 hours at room temperature and next with peroxidase donkey anti-chicken antibody (Stratech, 703035-155-JIR) for 1 hour at room temperature. Peroxidase was detected with DAB substrate kit (Vector Laboratories, SK-4100) according to manufacturer's instructions. Cells were counterstained with Harris Modified Hematoxylin Solution (Sigma-Aldrich, HHS32)) for 10 
minutes.

\section{Colony forming assays}

For evaluation of erythroid potential from progenitor populations, cells were seeded in Methocult M3436 and myeloid potential was evaluated with Methocult M3534. Colonies were scored after 8 days of culture. CFU-Mix colonies were scored in Methocult M3434 based on colonies containing red cells after 8 days of culture. Megakaryocytic potential was evaluated using the Megacult collagen-based assay. All these media were from StemCell Technologies, Vancouver, Canada. Megakaryocyte cultures were supplemented with 10ng/ml mIL-3, 20ng/ml hIL-6 (Peprotech), 50ng/ml hIL-11 (Peprotech), 50ng/ml hThpo (Peprotech), and megakaryocytes detected using acetylthiocholiniodide staining (Sigma) according to manufacturer's instructions after 7-8 days culture. For evaluation of $\mathrm{Mk}$ potential from single $\mathrm{GE}^{+}$and $\mathrm{GE}^{-} \mathrm{Lin}^{-} \mathrm{Sca}-1^{+} \mathrm{c}-\mathrm{Kit}^{+} \mathrm{Flt} 3^{\mathrm{hi}}$ cells, these cells were sorted into X-vivo15 medium containing glutamax and gentamycin (BioWhittaker) supplemented with $10 \%$ fetal calf serum (Hyclone), $10^{-4} \mathrm{M} \beta$-mercaptoethanol, 50ng/mL mSCF, 50ng/mL hFLT3 ligand (hFL; Immunex), 50ng/mL hThpo, 20ng/mL mIL-3 and $5 \mathrm{U} / \mathrm{ml}$ hEPO (Roche). For each experiment, 240 cells were manually plated at 1 cell per well into 60 well Terasaki plates. Mk potential was evaluated 8 or 12 days after culture using an inverted microscope.

\section{Measurement of lymphoid lineage potentials}

$\mathrm{B}$ and $\mathrm{T}$ lymphocyte potentials of purified progenitor populations were evaluated following coculture on OP9 and OP9-DL1 stroma cells, respectively (kindly provided by Dr. A. Cumano, Pasteur Institute, Paris, France). LMPPs, $\mathrm{GE}^{+}$and $\mathrm{GE}^{-}$pre-GMs, and $\mathrm{GE}^{+}$and $\mathrm{GE}^{-} \mathrm{GMPs}$ were seeded onto stromal monolayers. OP9 cultures were supplemented with $25 \mathrm{ng} / \mathrm{ml} \mathrm{mSCF}, 25 \mathrm{ng} / \mathrm{ml}$ hFL (Peprotech) and 10ng/ml hIL-7 (Peprotech), while OP9-DL1 cultures were supplemented with $25 \mathrm{ng} / \mathrm{ml} \mathrm{mSCF}$ and $25 \mathrm{ng} / \mathrm{ml} \mathrm{hFlt3L}$. SCF was removed after 7 days of culture. Readout was by FACS at 14-21 days of culture. B cells were defined as $\mathrm{CD}_{1} 9^{+}$and $\mathrm{T}$ cells were defined as $\mathrm{CD} 4^{+} \mathrm{CD} 8^{+}$and/or Thy $1.2^{+} \mathrm{CD} 25^{+}$(Supplementary Fig. 4e,f).

\section{Quantitative PCR}

For gene expression analysis of bulk cultures and cultured cell populations, RNA was purified from 2000-6000 cells per replicate with Trizol (Invitrogen, Carlsbad, CA, USA) and reversetranscribed with SuperScript VILO cDNA synthesis kit according to the manufacturer's instructions (Invitrogen, Carlsbad, CA, USA). For single cells and progenitor populations (200 
cells per replicate), CellsDirect ${ }^{\mathrm{TM}}$ One-Step qRT-PCR kit (Life technologies, 11753-100) was used according to manufacturer's protocol for preparation and amplification of cDNA. The BioMark 96.96, 48.48 or 192.24 Dynamic Array platform (Fluidigm) and either Taqman ${ }^{\circledR}$ assays (for progenitor populations and single cells) or the Universal probe library system (Roche) (for bulk cultures and cultured cell populations) were used according to the manufacturers' instructions. UPL primers and probes were chosen by the Assay Design Center web service for mouse genes. Default parameters were used and highest-ranking primers-probe combination was chosen for each gene.

\section{Analysis of quantitative PCR of single cells}

$\Delta \mathrm{Ct}$ values relative to $\mathrm{Hprt}(\mathrm{Ct}(\mathrm{Hprt})$ - $\mathrm{Ct}(\mathrm{Gene}))$ were zero centered for each gene by subtraction of the mean value of all positive cells for the gene. These normalized values were used to generate heat maps using GENE-E software.

\section{Microarray gene profiling and bioinformatics analysis}

Global gene expression was analyzed in FACS purified HSCs, LMPPs, CLPs, $\mathrm{EGFP}^{+}$and EGFP pre-GM, GE ${ }^{+}$and $\mathrm{GE}^{-}$GMPs, and pre-MegEs. For all cell populations, 3-4 individually sorted samples from different pools of mice were prepared. For each sample, 5000 cells were sorted directly into RLT buffer (Qiagen) and RNA was extracted according to the manufacturer's instructions (Qiagen). Microarray analysis was performed by the Paterson Institute Microarray Service, Manchester UK, using MoGene 1.0ST arrays. Data were RMA normalized ${ }^{56}$. Custom R scripts were used to perform principal component analysis (PCA) on 2,305 genes that showed high variation of gene expression across populations (ANOVA with adjusted $P$ values $<0.05$ and coefficient of variation (CV) equal to or larger than 0.4). GSEA $^{27}$ was performed using CLP and preMegE gene sets previously described ${ }^{6}$.

\section{Single cell RNA sequencing; cell capture and preparation of cDNA}

5000 pre-GM cells from wild type C57BL/6 male mice (CD45.1) were sorted in $2 \mu 1$ PBS $/ 50 \%$ FCS. Single cells were captured on a small-sized $\left(5-10 \mu \mathrm{m}\right.$ cell diameter) $\mathrm{C}_{1}{ }^{\text {TM }}$ SingleCell Auto Prep IFC for mRNA Sequencing (Fluidigm) using the Fluidigm C1 system. Cells were loaded onto the chip at a concentration of $\sim 300$ cells/ $\mu$ land imaged by phase-contrast microscopy to check single cell per capture site. 64 cells were captured and used for RNA-seq. Cells were lysed and cDNA prepared on the $\mathrm{C} 1$ fluidigm chip according to manufacturer's protocol, using SMARTer Ultra Low RNA kit for Illumina (Clontech). 


\section{Single cell RNA sequencing; library construction}

Single-cell Library size distribution was checked on a High-Sensitivity DNA chip (Agilent Bioanalyzer) (average concentration $239 \mathrm{pg} / \mu \mathrm{l}$, SD 149pg/ $\mu \mathrm{l}$ ). 1ng of cDNA was used for tagmentation with Nextera XT DNA Sample Preparation kit (Illumina). Purification was done with a 1:1 ratio of AMPure XP beads with a final elution in $25 \mu 1$ of Resuspension Buffer (Nextera). Samples were loaded on a High-Sensitivity DNA chip to check the size and quality of the indexed library (average size 612bp, SD 104), while quantification was done with Qubit HighSensitivity DNA kit (Invitrogen) (average concentration 347ng/ml SD 95). Libraries were pooled to a final concentration of $10 \mathrm{nM}$ and were sequenced with Illumina HiSeq 2000 (single end 50 basepair reads) at The Wellcome Trust Centre for Human Genetics at the University of Oxford.

\section{Single cell RNA sequencing; data analysis and visualization}

$51 \mathrm{bp}$ reads were aligned to the murine genome $(\mathrm{mm} 9)$ using STAR ${ }^{57}$ and default parameters. See (Supplementary Fig. 8) for the information about the number of uniquely mapped reads, percentage of mapping, and the number of detected genes per each single cell). Non-uniquely mapped reads were discarded. Transcript expression values were quantified using Cufflinks ${ }^{58}$ as fragments per kilobase of transcript per million mapped reads (FPKM). Overlapping transcripts were collapsed giving the highest one expression value per gene loci. One cell was removed from the analysis due to the low detection number of genes (sample81, Supplementary Fig. 8). Custom R scripts were used to perform PCA, hierarchical clustering, and visualization on the $\log 2$ of FPKM scale. In brief, PCA analysis was performed on all cells using all genes, which have the average expression values $>=1$. We selected top 100 genes with the highest absolute correlation coefficient (PCA component loadings) in one of the first three components for the hierarchical clustering analysis. Genes differentially expressed between the two main cellular were identified using ANOVA $(\mathrm{P}<0.001 ; \mathrm{FDR}<0.05)$ and used for the final clustering of single cells.

\section{Statistical analysis}

Student's t-test was used to determine statistical significance for normally distributed data. For single cell expression levels the Mann-Whitney U-test was used, and Fisher's exact test was used to compare expression frequencies at the single cell level between populations. No statistical method was used to predetermine sample size, and experiments were not randomized. No data were excluded from analysis. The Investigators were not blinded to allocation during experiments and outcome assessment. 


\section{Antibodies \\ Information on antibodies (including clone, concentration and vendor) is provided in Supplementary Dataset 2}

\section{Taqman assays}

Taqman assays: Information on these assays is provided in Supplementary Dataset 3.

\section{References.}

51. Moreira PN, Pozueta J, Giraldo P, Gutierrez-Adan A, Montoliu L. Generation of yeast artificial chromosome transgenic mice by intracytoplasmic sperm injection. Methods $\mathrm{Mol}$ Biol 2006, 349: 151-161.

52. McKenna HJ, Stocking KL, Miller RE, Brasel K, De Smedt T, Maraskovsky E, et al. Mice lacking flt3 ligand have deficient hematopoiesis affecting hematopoietic progenitor cells, dendritic cells, and natural killer cells. Blood 2000, 95(11): 3489-3497.

53. Lindeboom F, Gillemans N, Karis A, Jaegle M, Meijer D, Grosveld F, et al. A tissuespecific knockout reveals that Gata1 is not essential for Sertoli cell function in the mouse. Nucleic Acids Res 2003, 31(18): 5405-5412.

54. Kuhn R, Schwenk F, Aguet M, Rajewsky K. Inducible gene targeting in mice. Science (New York, NY 1995, 269(5229): 1427-1429.

55. Kanakura Y, Kuriu A, Waki N, Nakano T, Asai H, Yonezawa T, et al. Changes in numbers and types of mast cell colony-forming cells in the peritoneal cavity of mice after injection of distilled water: evidence that mast cells suppress differentiation of bone marrow-derived precursors. Blood 1988, 71(3): 573-580.

56. Irizarry RA, Hobbs B, Collin F, Beazer-Barclay YD, Antonellis KJ, Scherf U, et al. Exploration, normalization, and summaries of high density oligonucleotide array probe level data. Biostatistics 2003, 4(2): 249-264.

57. Dobin A, Davis CA, Schlesinger F, Drenkow J, Zaleski C, Jha S, et al. STAR: ultrafast universal RNA-seq aligner. Bioinformatics 2013, 29(1): 15-21.

58. Roberts A, Pimentel H, Trapnell C, Pachter L. Identification of novel transcripts in annotated genomes using RNA-Seq. Bioinformatics 2011, 27(17): 2325-2329. 
a

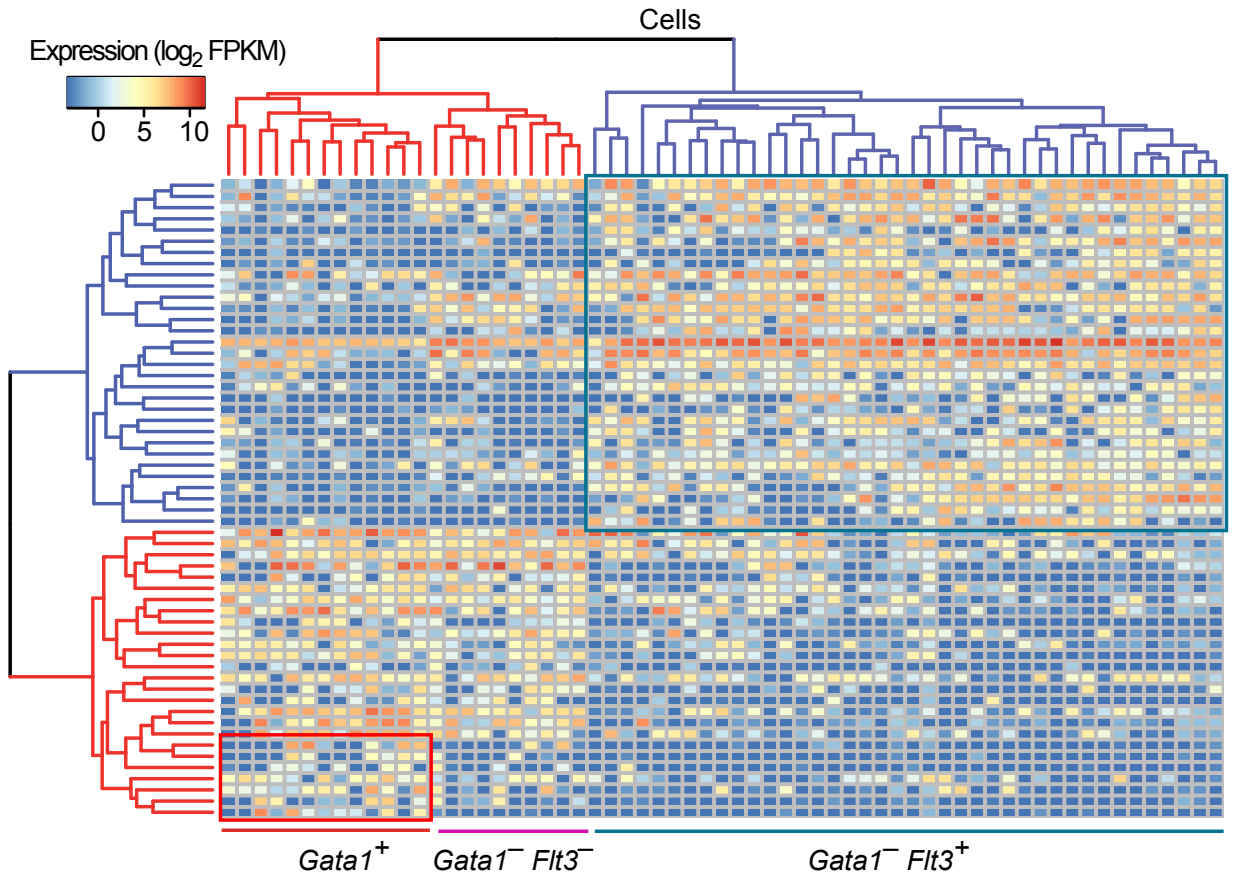

b

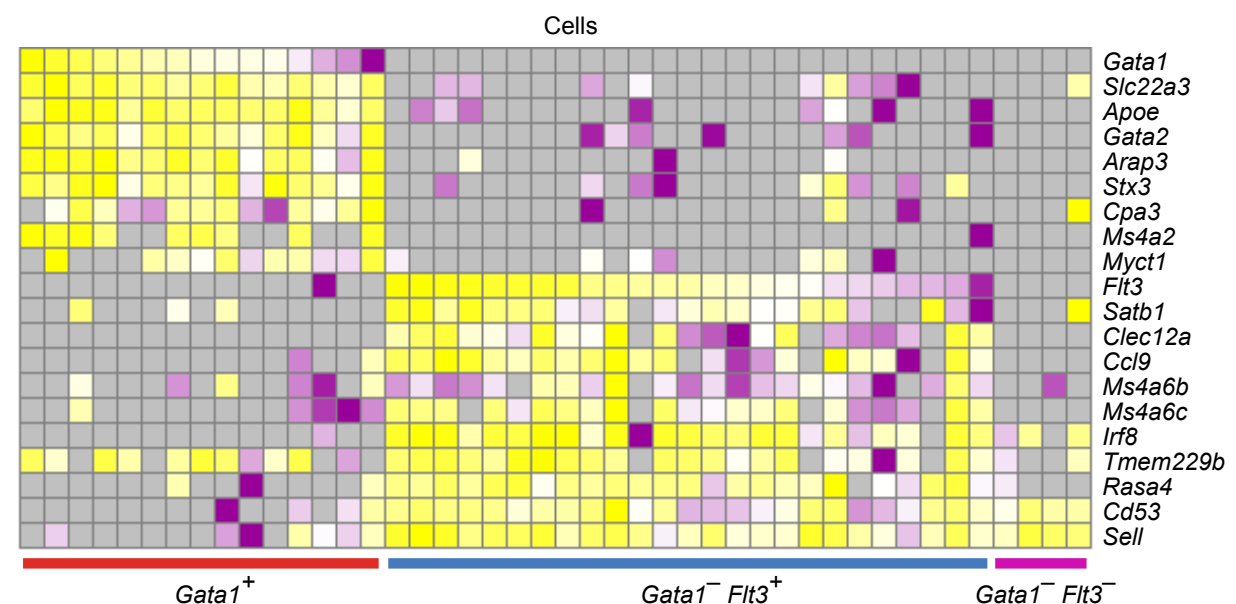

Expression ( $\left.\log _{2} \mathrm{mRNA}\right)$

f
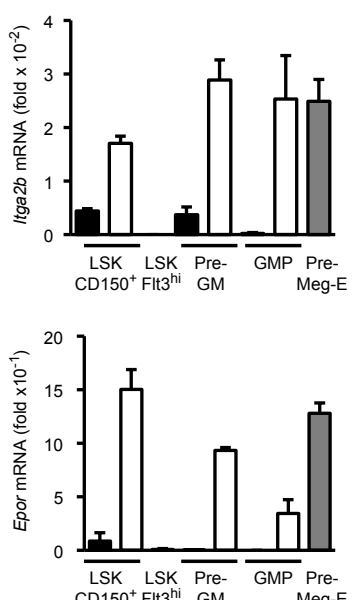

i

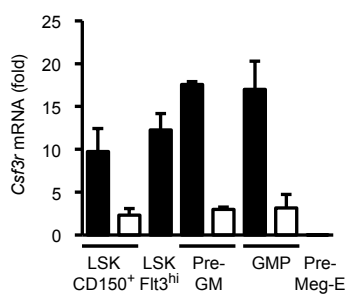

g
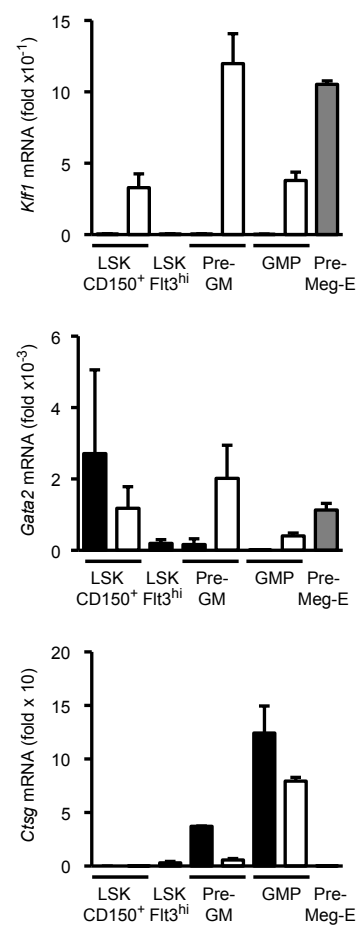
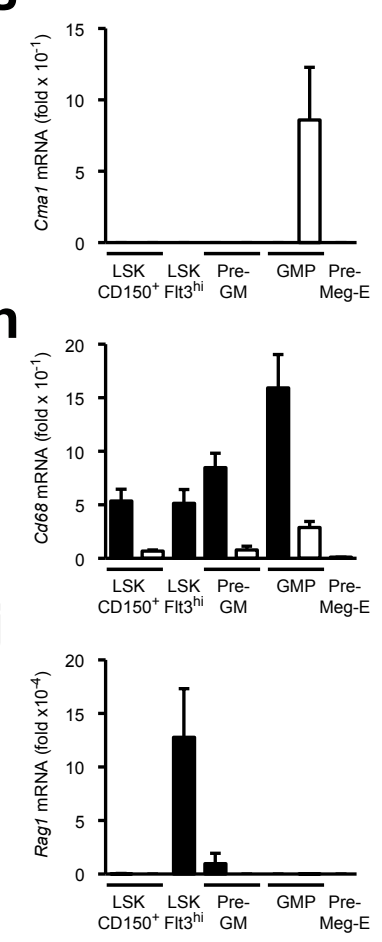

Fig. 1
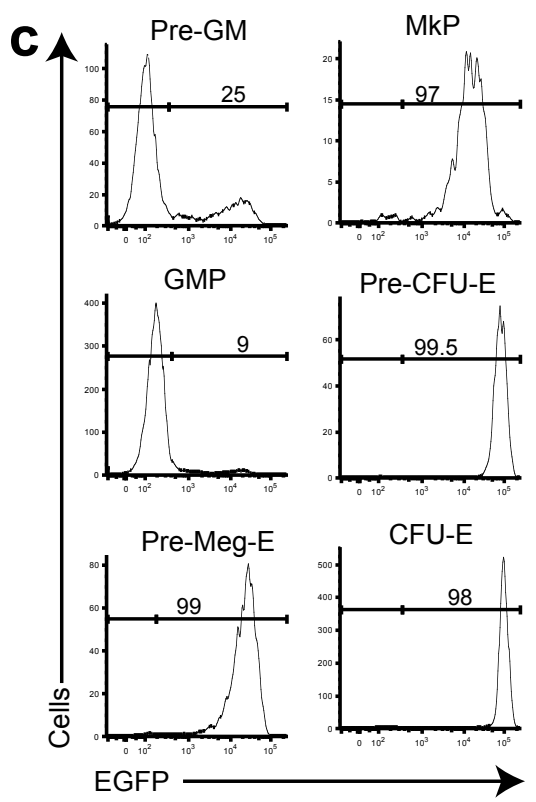

d

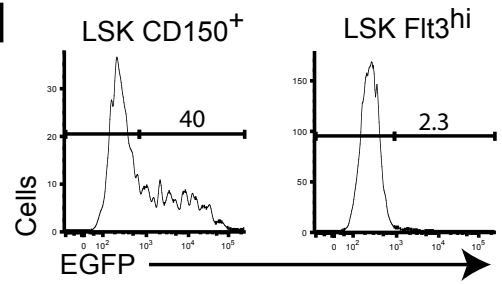

e

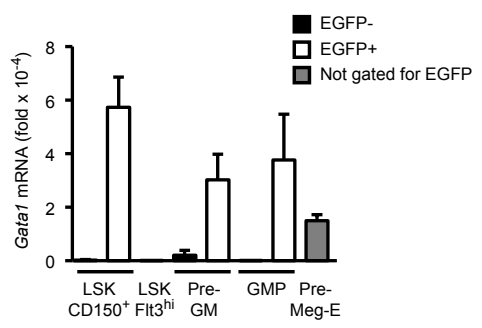

k
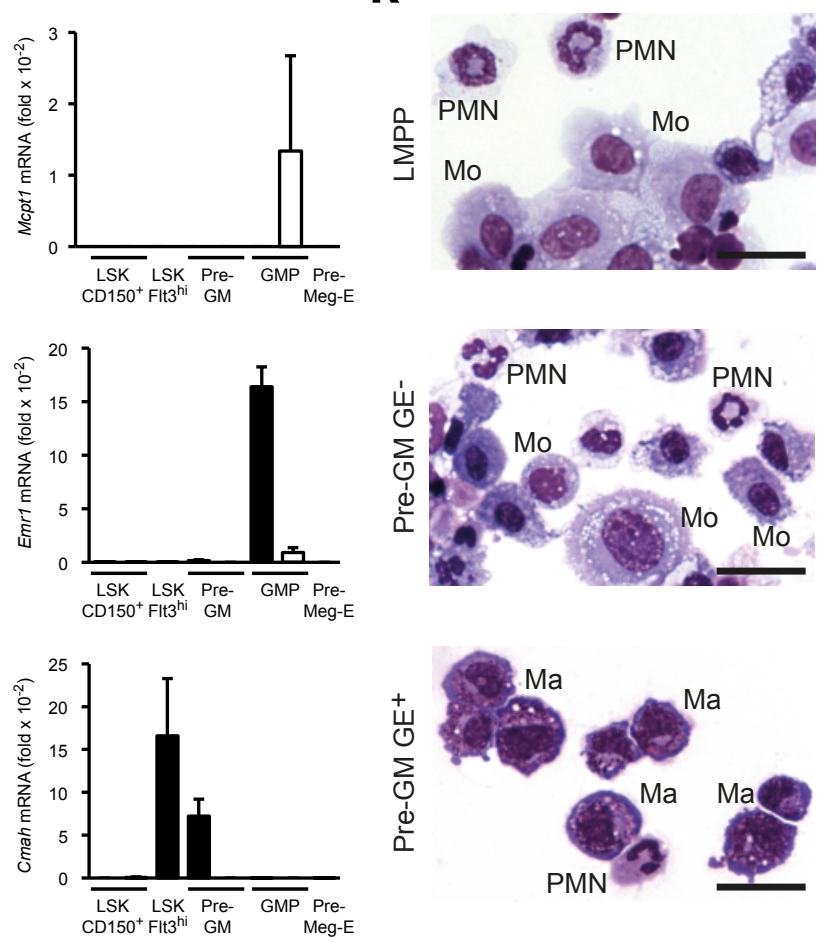
a

b
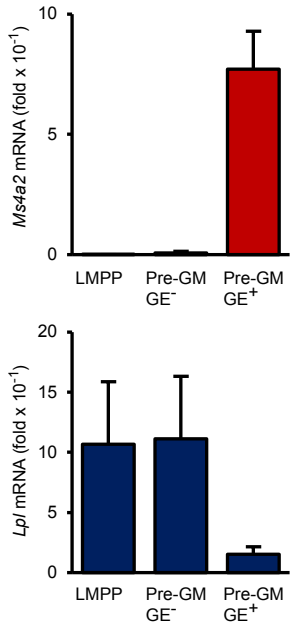

C

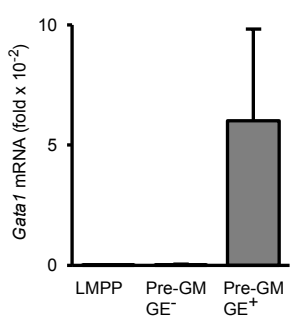

d

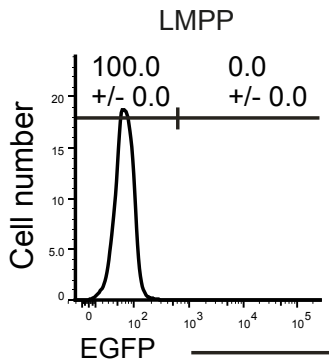

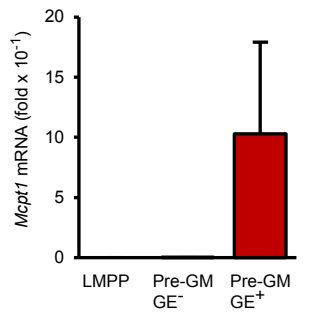
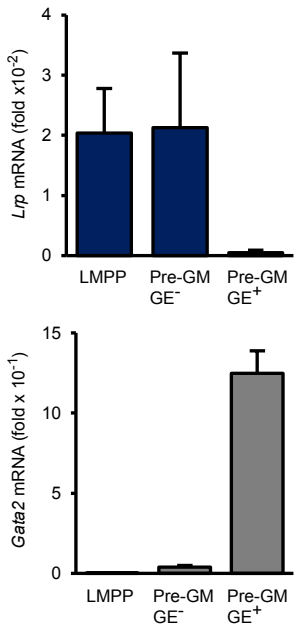

Pre-GM GE-

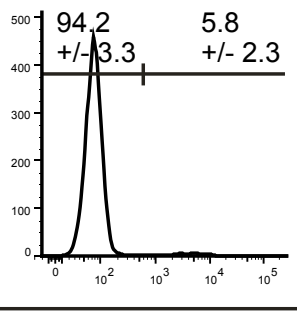

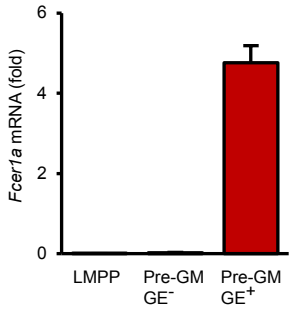
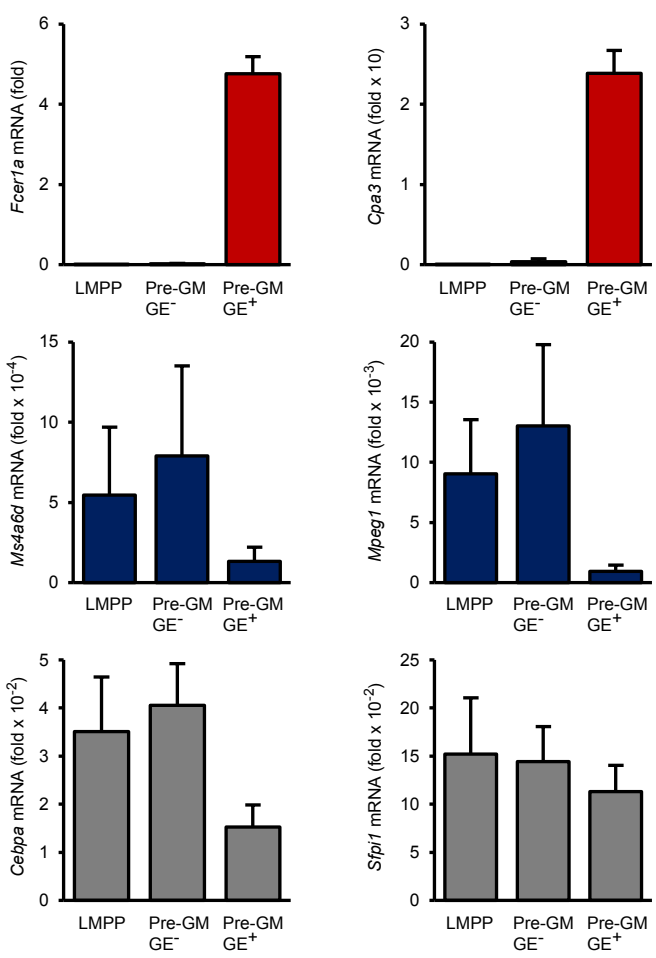

e
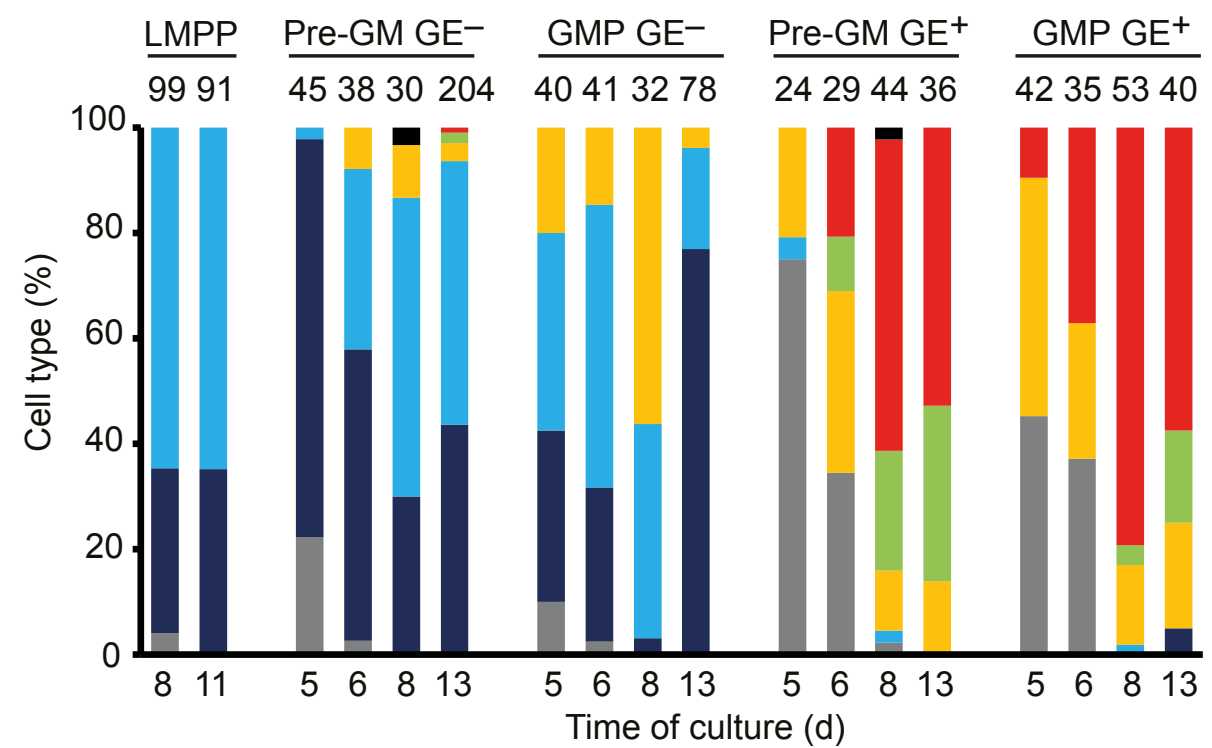

Pre-GM GE ${ }^{+}$

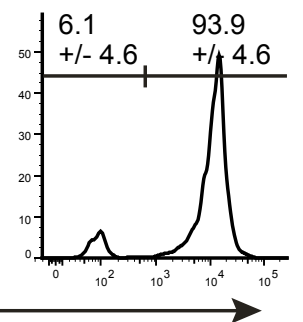

Time of culture (d)

f
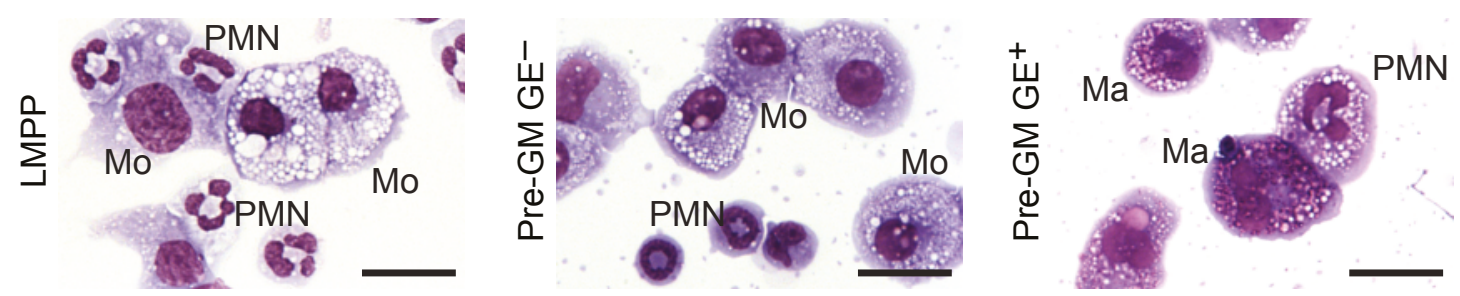

Fig. 2 
a

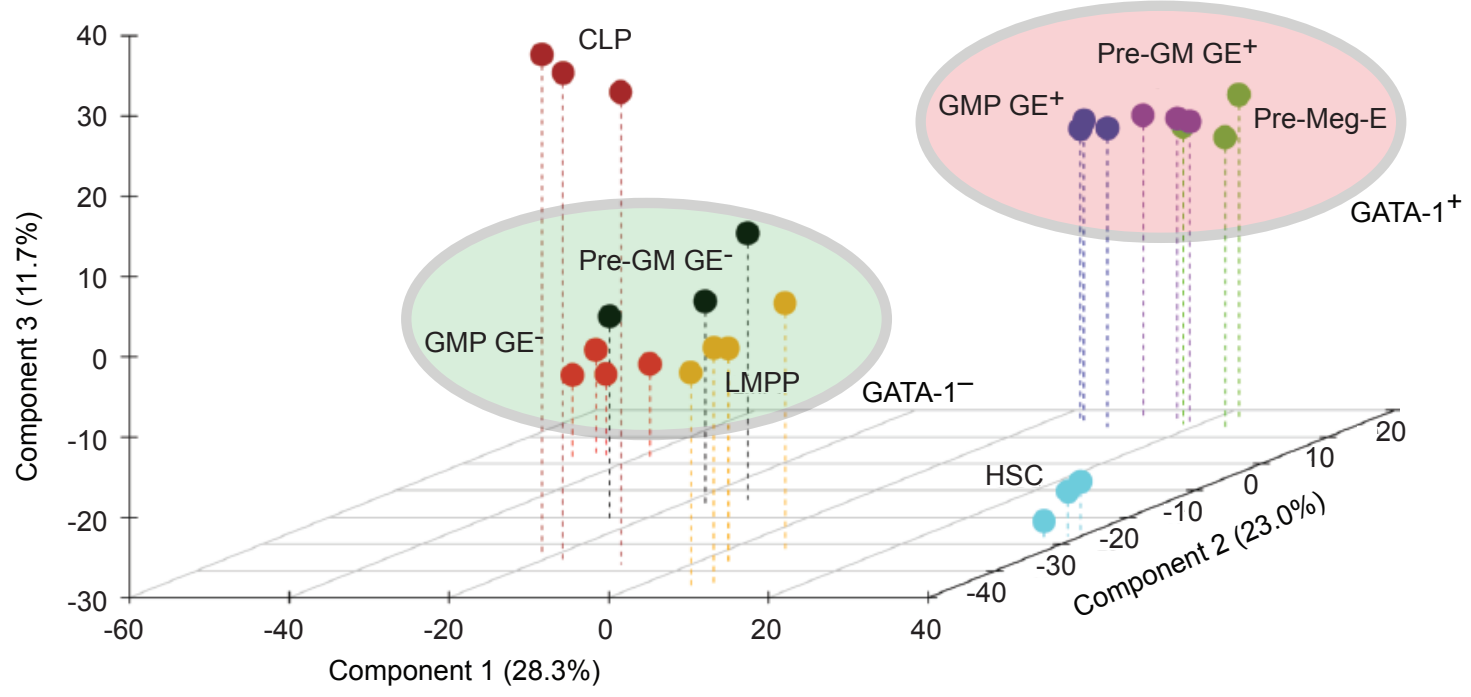

b

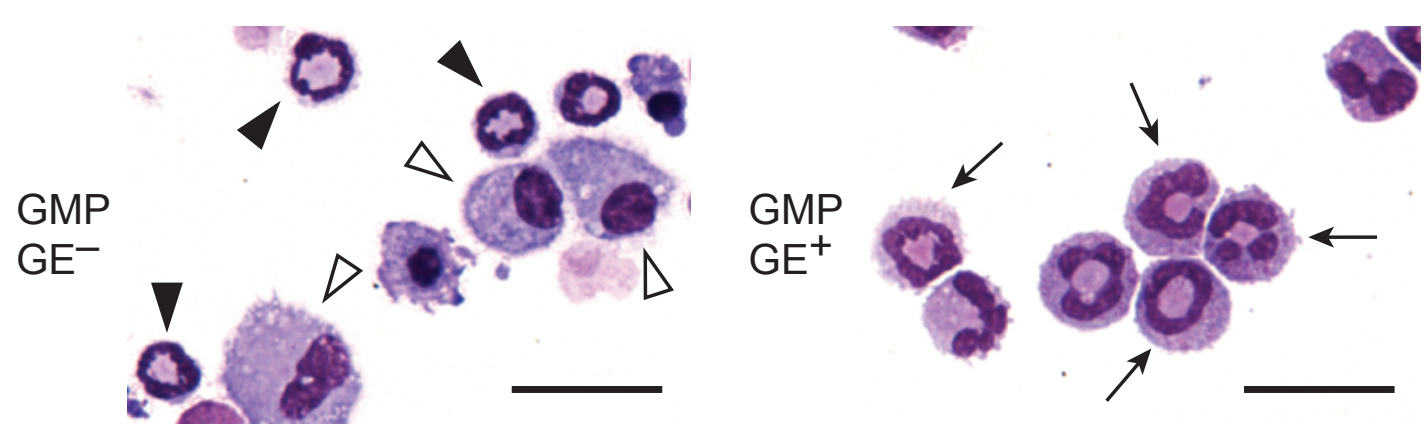

C
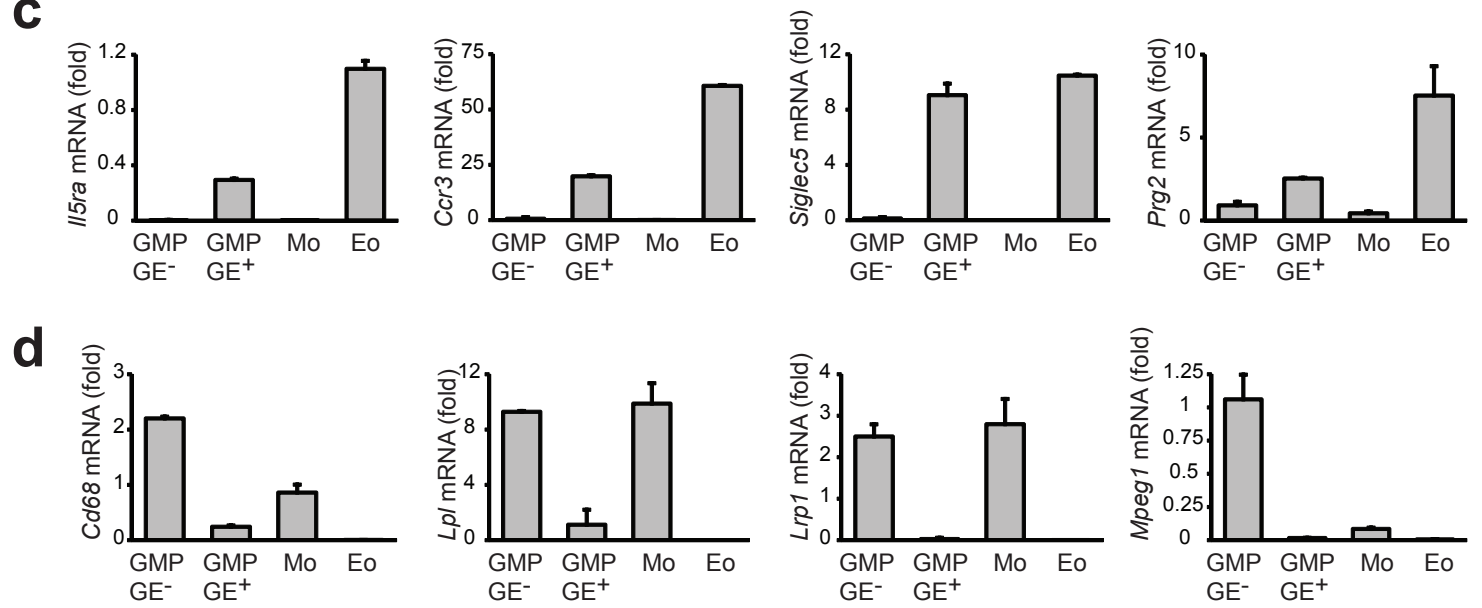

Fig. 3 

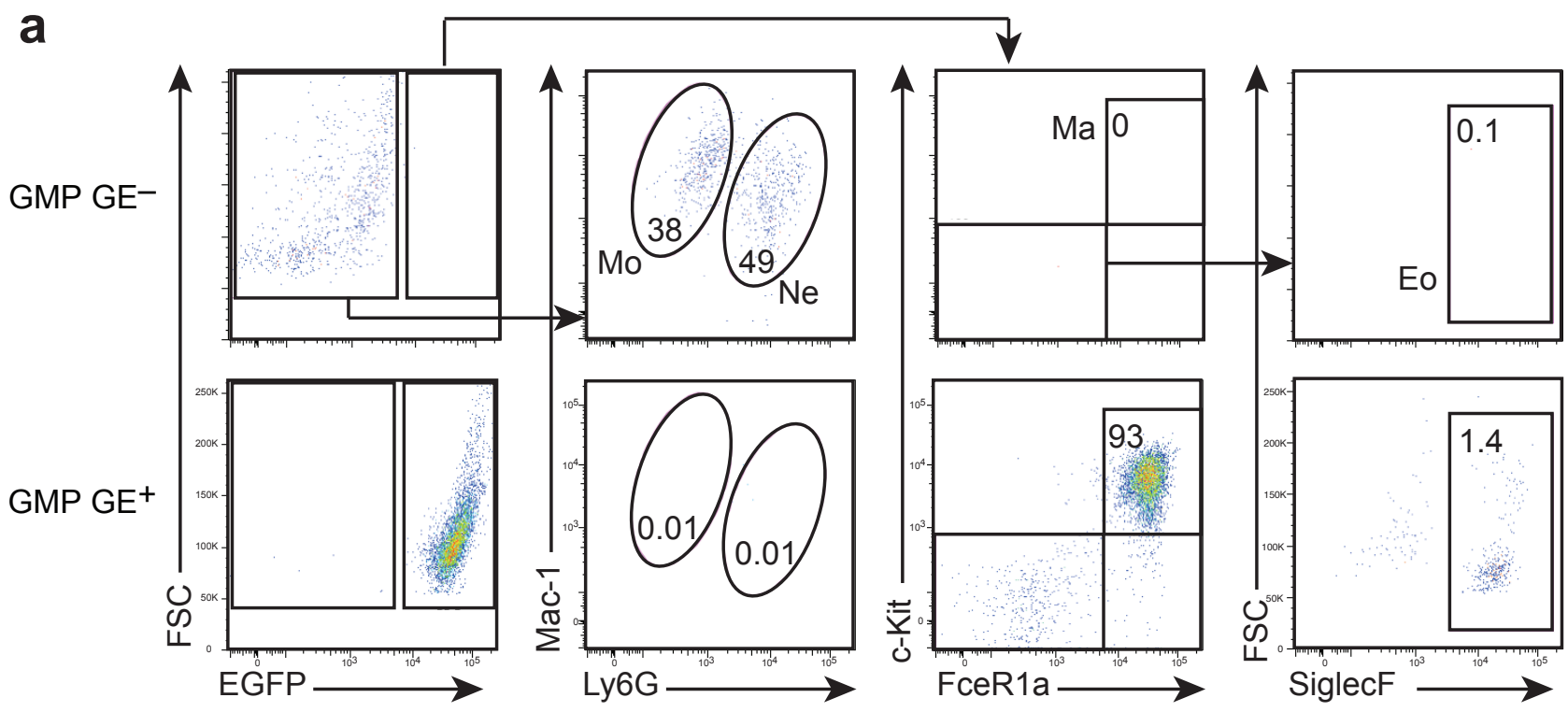

b

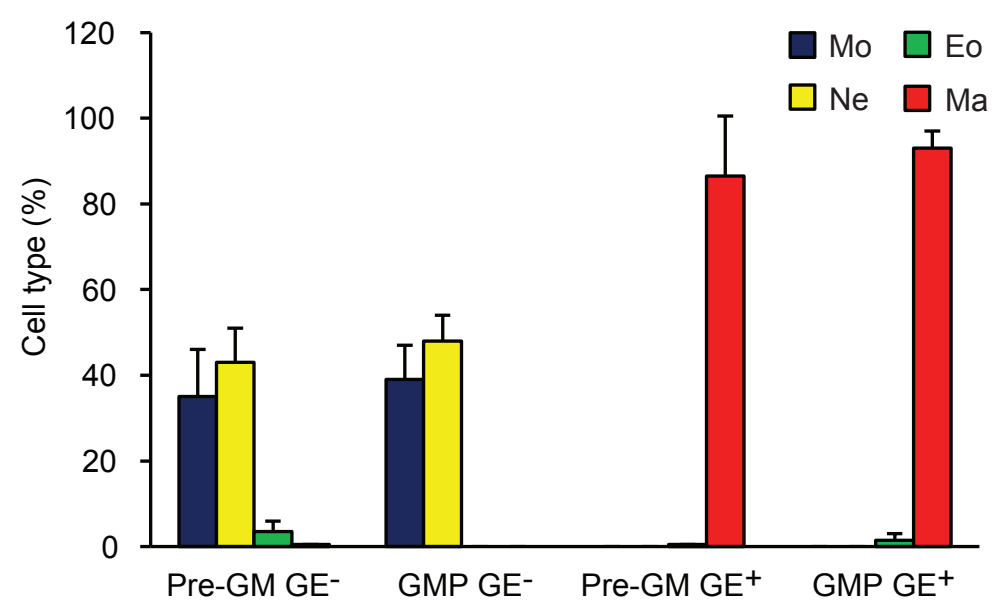

C

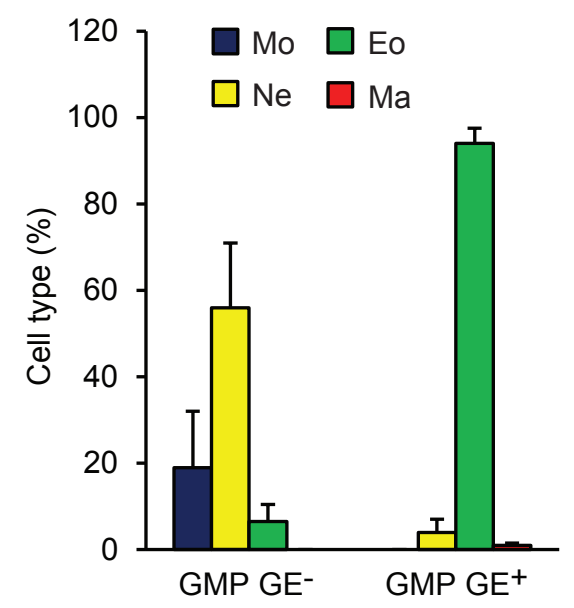

d
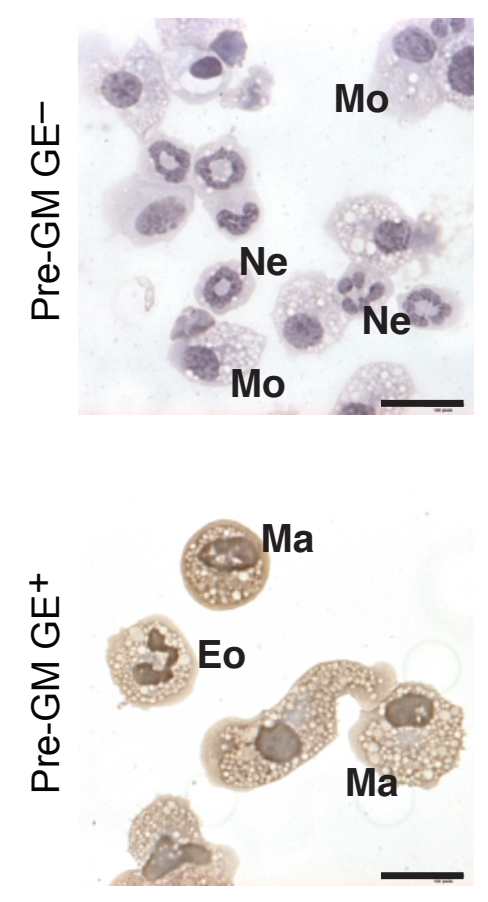

e

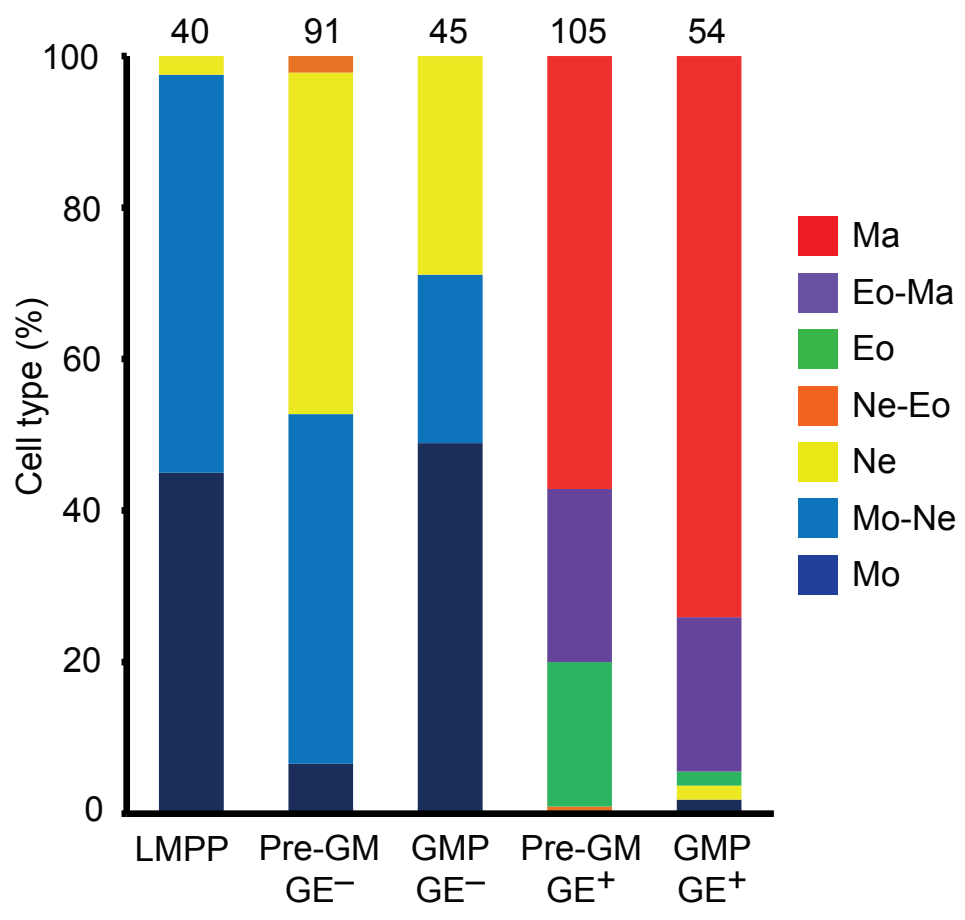


a

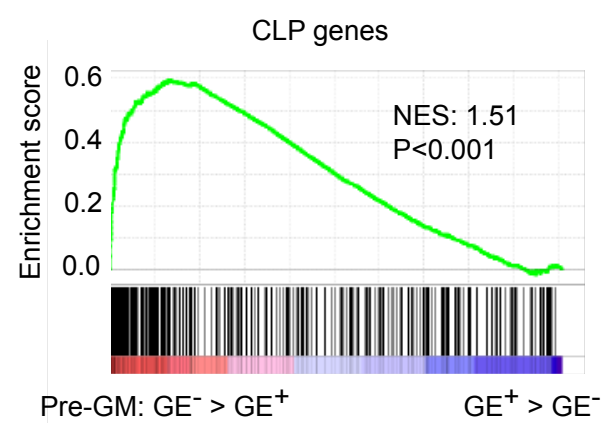

Rank in ordered data set

Pre-Meg-E genes

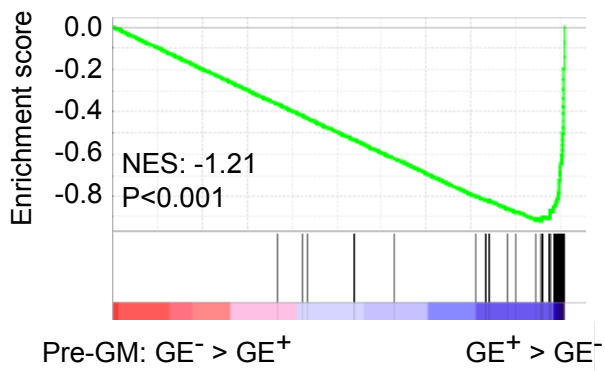

Rank in ordered data set

f

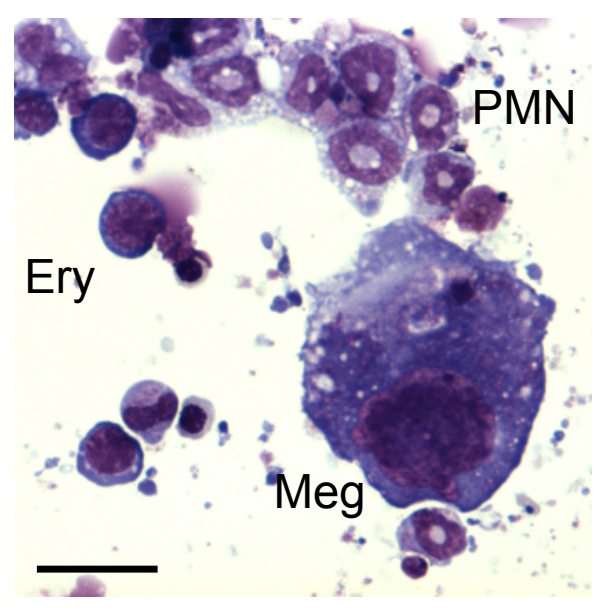

$\mathrm{Ma}$

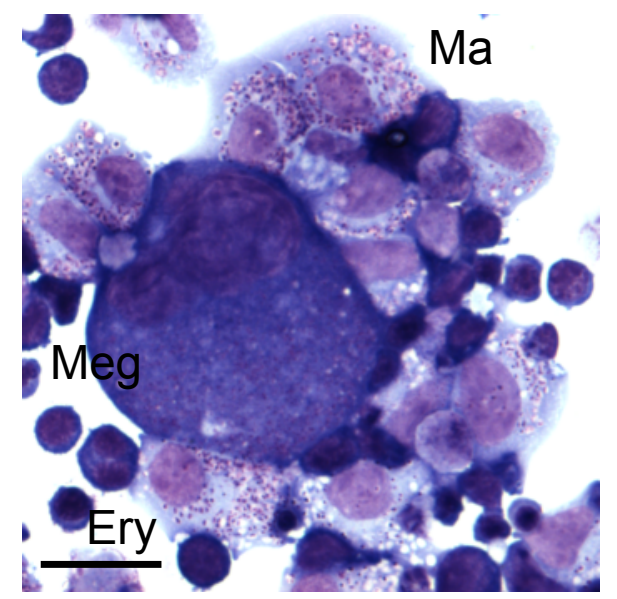

b

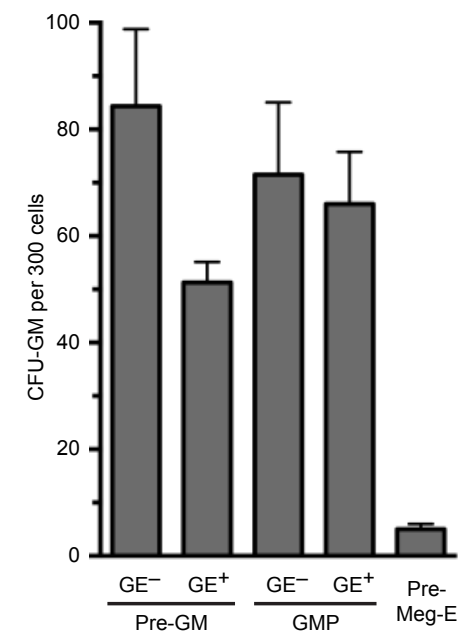

d

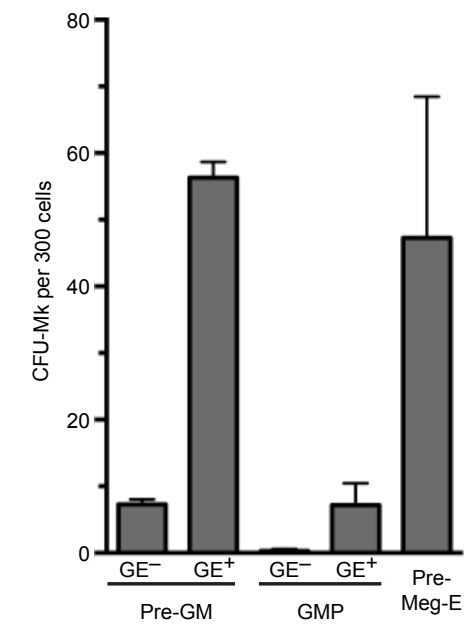

g
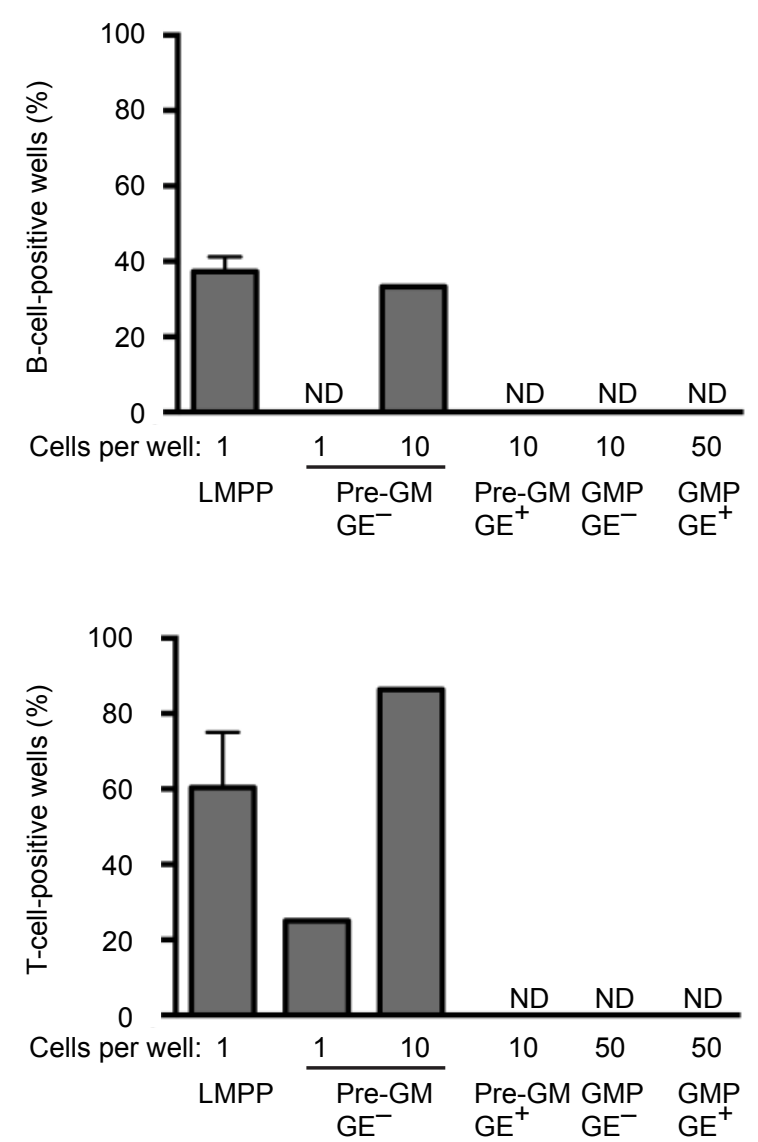

Fig. 5 

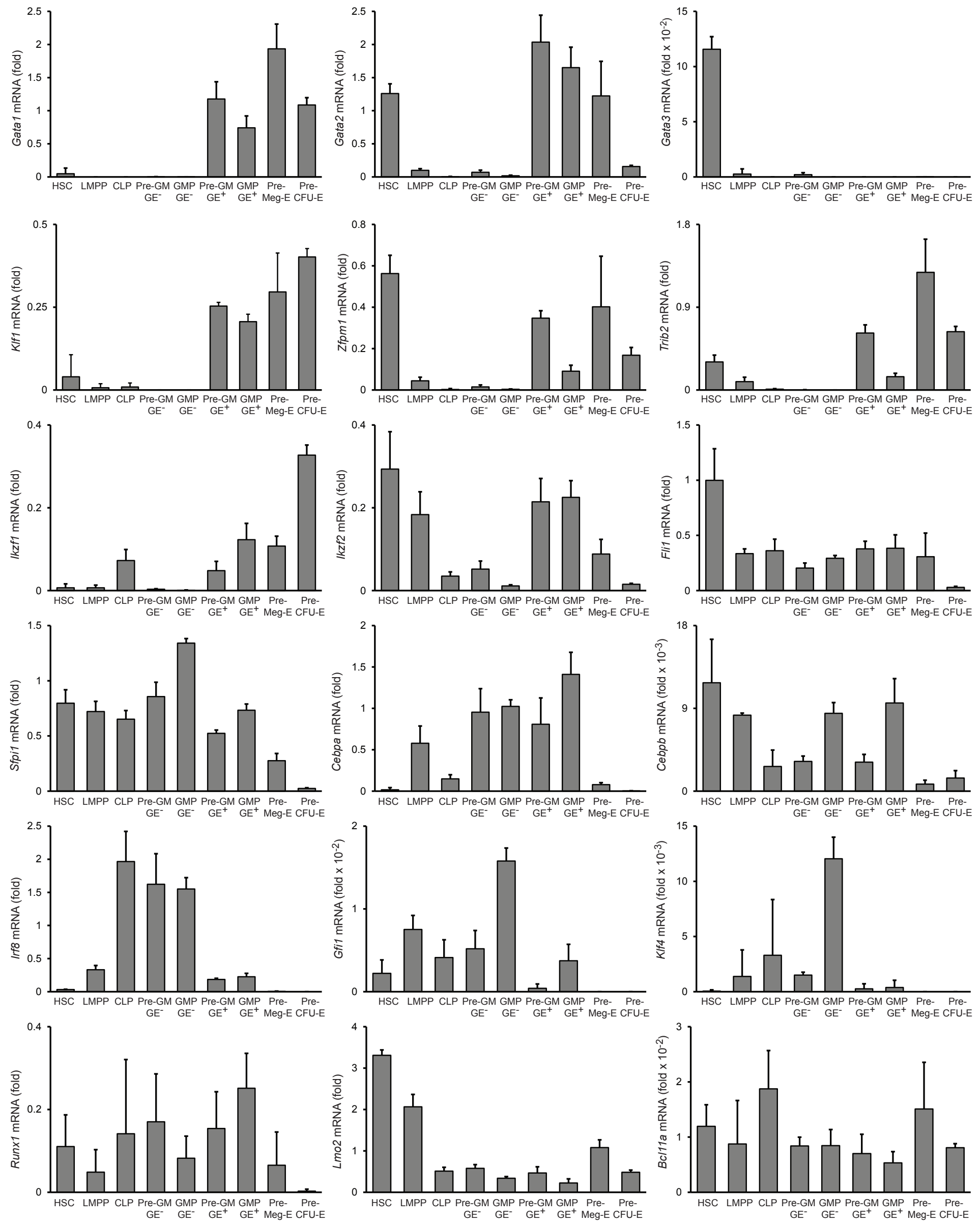

Fig. 6 
a

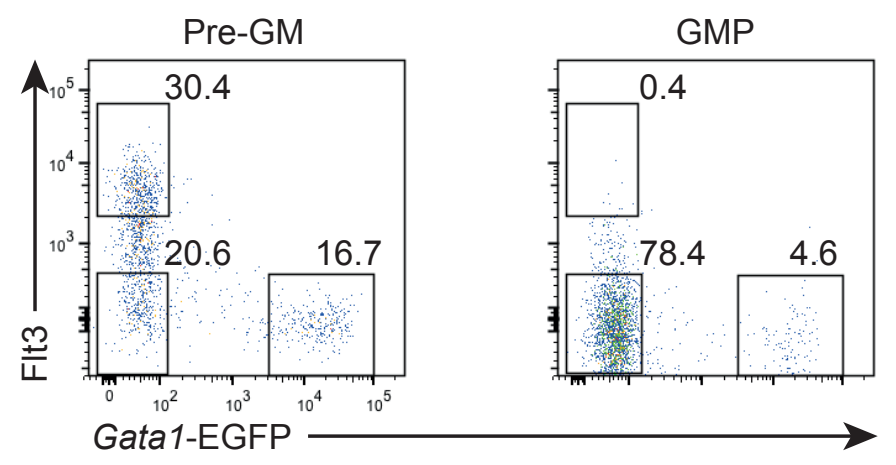

b

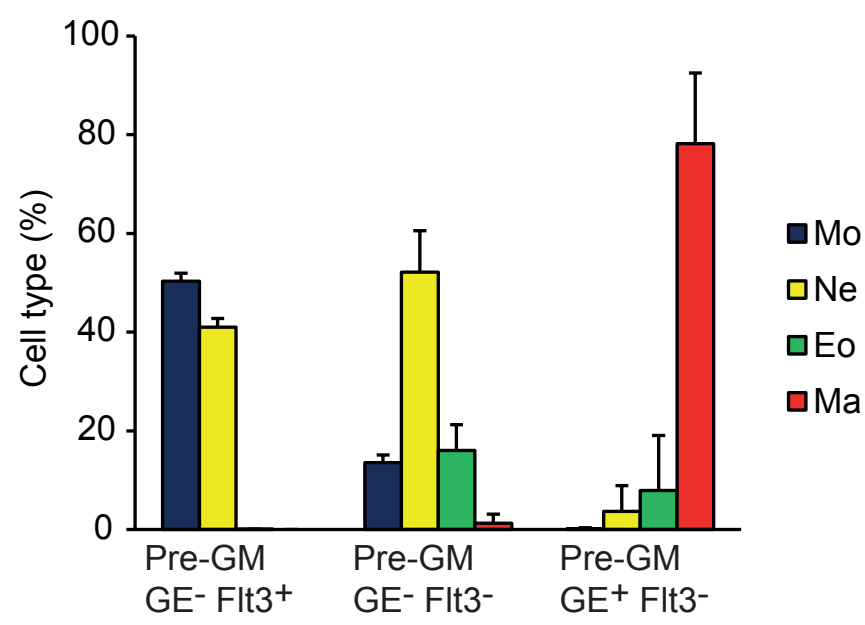

C

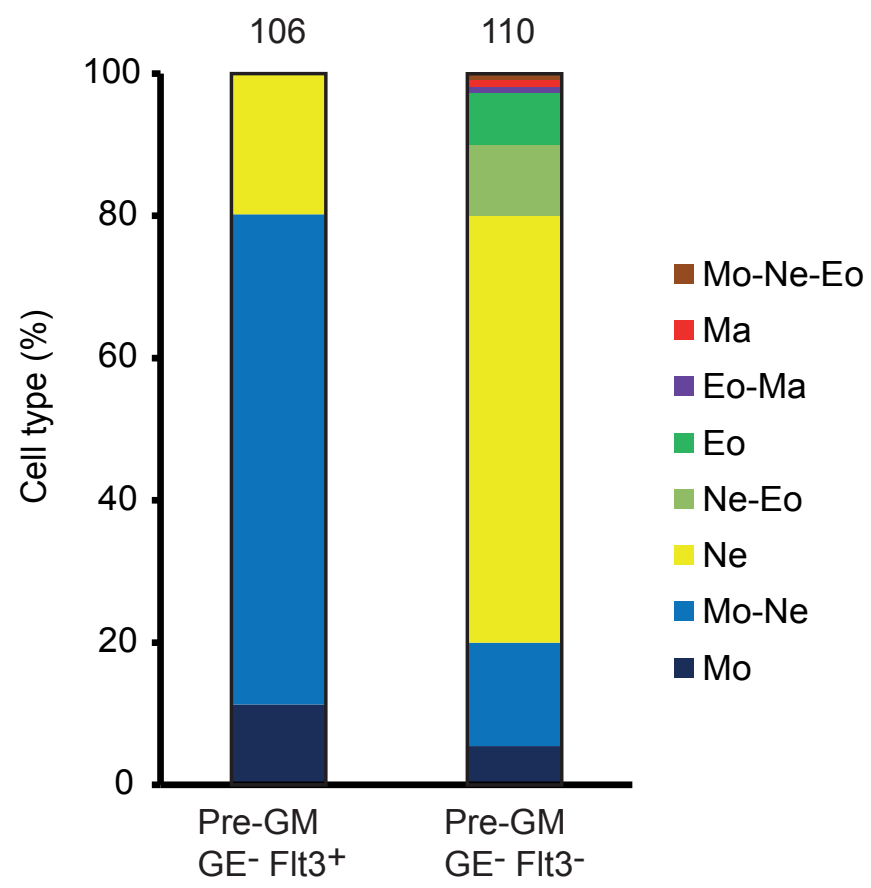

d

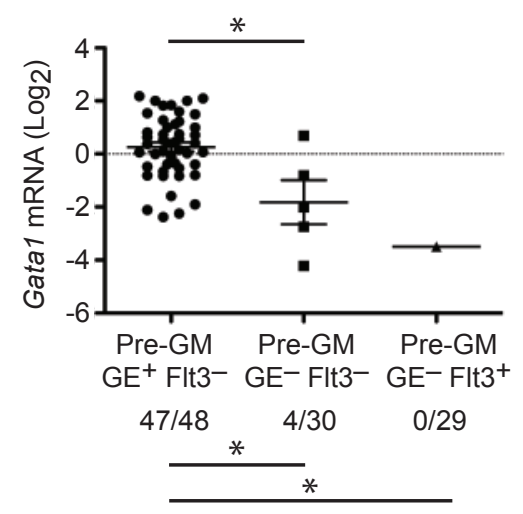

g $\mathrm{Ne}$ Mk-E MaMo

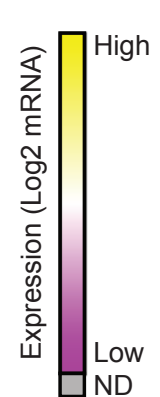
o

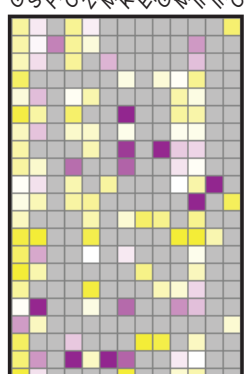

Pre-GM $\mathrm{GE}^{+}$Flt3-

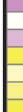

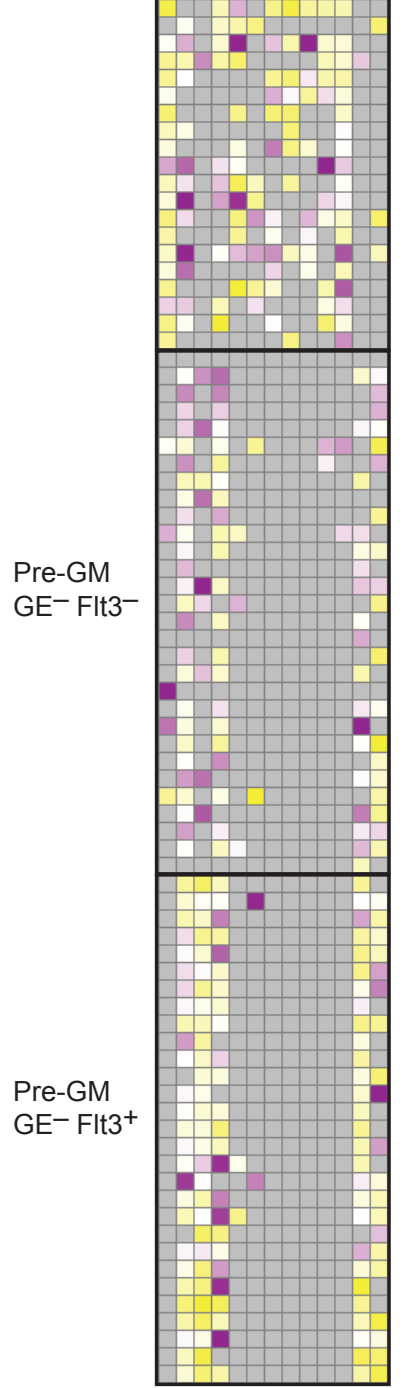

f

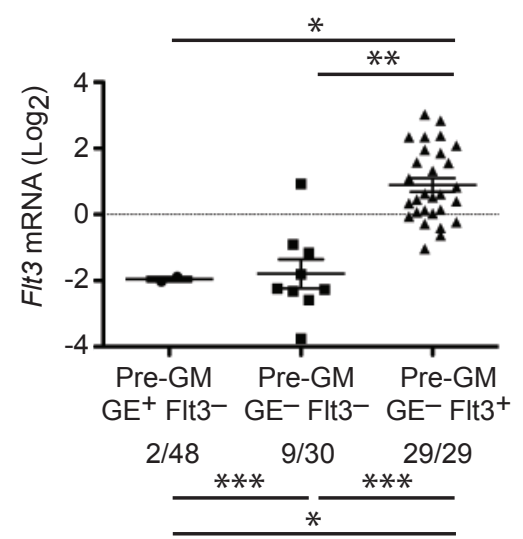

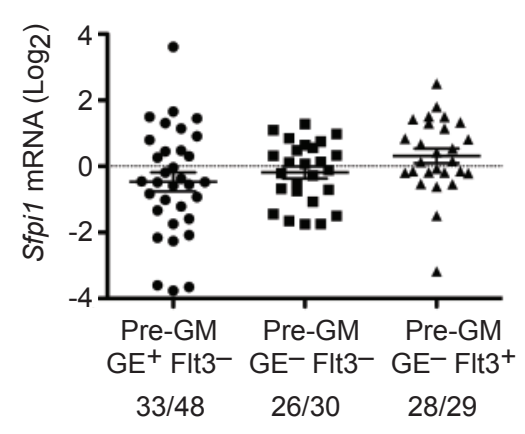

Fig. 7 
a

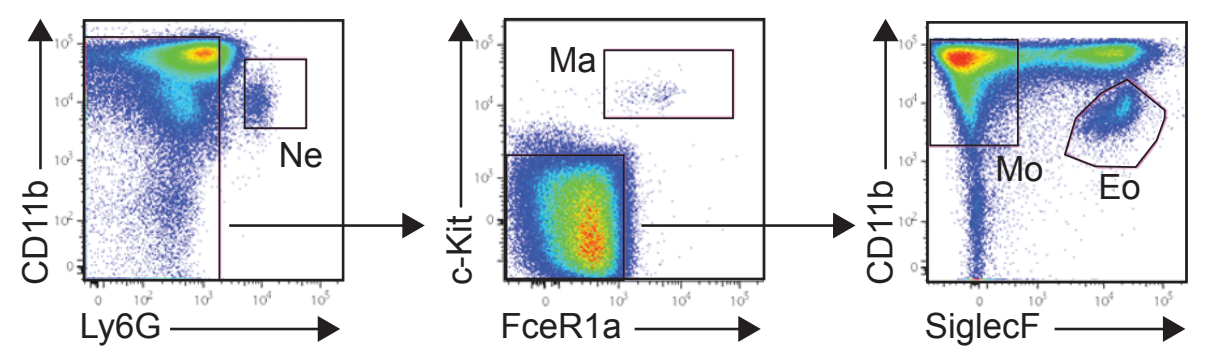

b

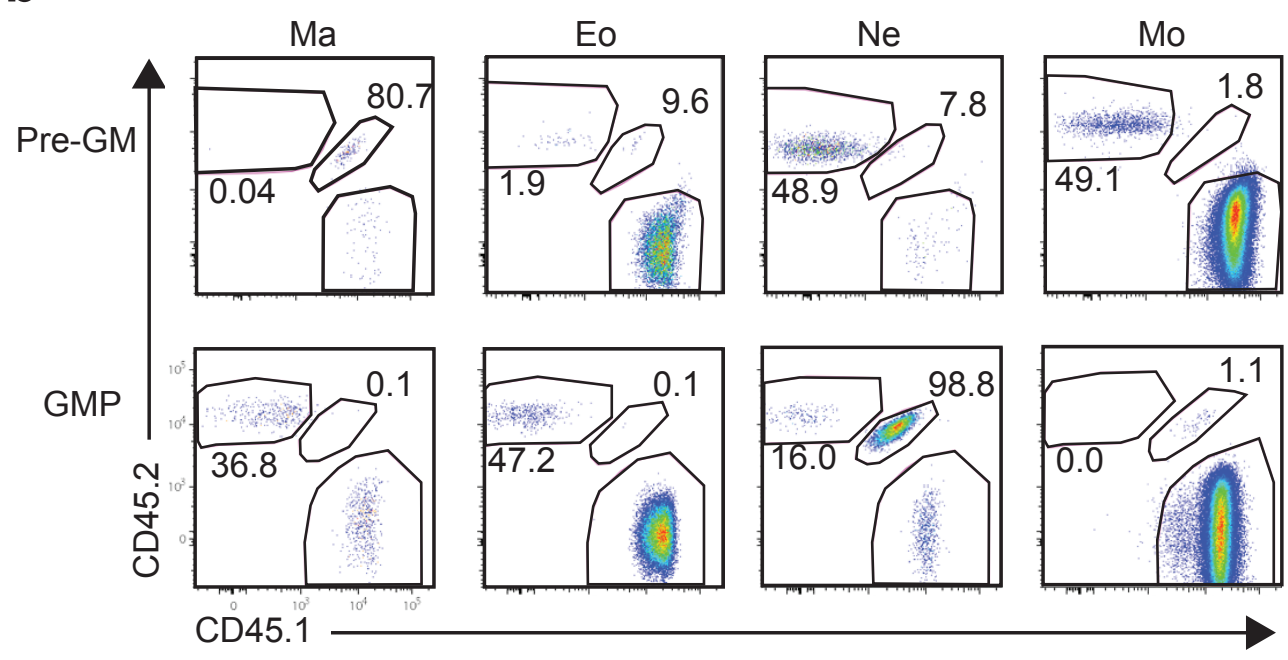

C

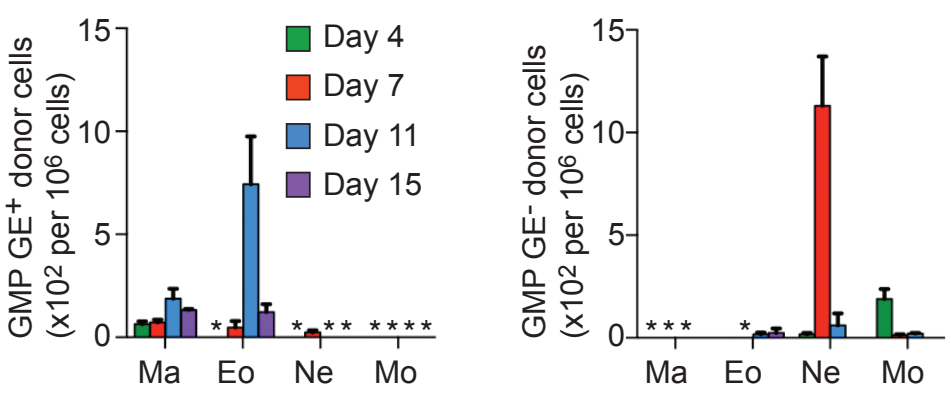

e

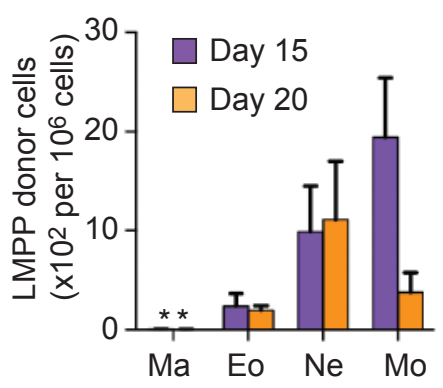

d
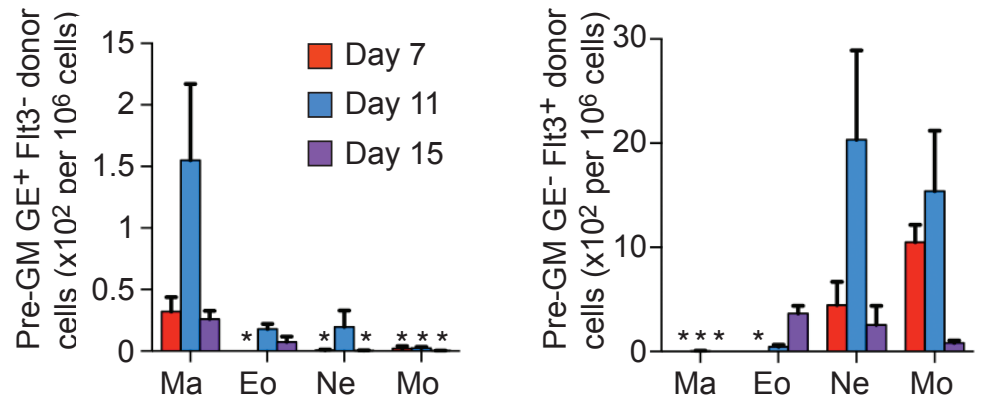

Fig. 8 